Post-Occupancy Evaluation of the Forrestal Building

\section{Philip A. Sanders Belinda L. Collins}

U.S. DEPARTMENT OF COMMERCE Technology Administration National Institute of Standards and Technology

Building and Fire Research Laboratory Gaithersburg, MD 20899

Prepared for:

U.S. Department of Energy Washington, D.C.

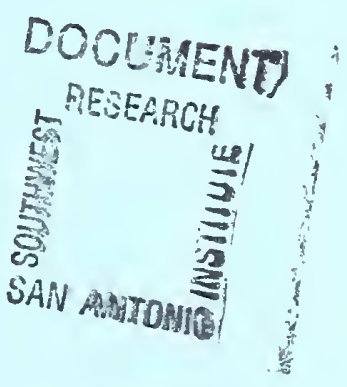





\title{
Post-Occupancy Evaluation of the Forrestal Building
}

\section{Philip A. Sanders Belinda L. Collins}

\author{
U.S. DEPARTMENT OF COMMERCE \\ Technology Adminis tration \\ National Institute of Standards \\ and Technology \\ Building and Fire Research Laboratory \\ Gaithersburg, MD 20899 \\ Prepared for: \\ U.S. Department of Energy \\ Washington, D.C.
}

March 1995

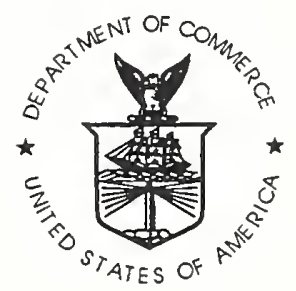

U.S. DEPARTMENT OF COMMERCE Ronald H. Brown, Secretary

TECHNOLOGY ADMINISTRATION Mary L. Good, Under Secretary for Technology

NATIONAL INSTITUTE OF STANDARDS AND TECHNOLOGY

Arati Prabhakar, Director 


\begin{abstract}
A post-occupancy evaluation was performed on the Department of Energy Headquarters Building (the Forrestal Building) in Washington, D.C. The lighting in the building was retrofitted with new, more energy-efficient, components to meet energy target guidelines. Occupant responses to the indoor environmental conditions, particularly the lighting, were studied to determine the impact of the relighting on the building inhabitants. In addition, physical measures of the lighting and other environmental conditions before and after the relighting were compared. The post-occupancy evaluation employed a questionnaire about the environmental conditions and physical measures of the space (lighting, space, noise, temperature, etc.). A total of 244/220 people participated (before and after the relighting, respectively). Physical measures were taken at 100 work stations before the relighting and 75 after. Analysis of the physical measurement data indicated generally higher lighting levels with more even distribution of luminances in the offices. Occupant response to the changes in the lighting was generally quite positive. The relighting was perceived to have improved the appearance of the building substantially, as well as the lighting within individual workstations. Finally, guidance is given for doing postoccupancy evaluations as part of other relighting initiatives.
\end{abstract}

\title{
KEYWORDS:
}

building technology, contrast, energy efficiency, environmental assessment, federal relighting, illuminance, lighting, luminance, post-occupancy evaluation, temperature, VDT's. 


\section{FOREWORD}

This report summarizes research conducted from January 1993 to December 1994 under contract Number DE-AI01-94CE73288.

\section{ACKNOWLEDGEMENTS}

The authors wish to thank Lou Harris, Jim Vejda and Mike Shincovich of the U.S Department of Energy for their co-operation in arranging access to the building to collect the data and for working with us to develop the plans for data collection. The authors also wish to thank Steve Treado, NIST, for his insight on developing the automatic data collection device. In addition, the authors wish to thank Andy Persily and Wen Lu of the NIST Indoor Air Quality Group for their cooperation in collecting the physical measurement data. This report would not have been possible without their willing and enthusiastic help and support.

\section{DISCLAIMER}

Any commercial products or trade names mentioned in this report are included for informational purposes only, and do not constitute an endorsement or recommendation by the National Institute of Standards and Technology or the U.S. Department of Energy. 
1.

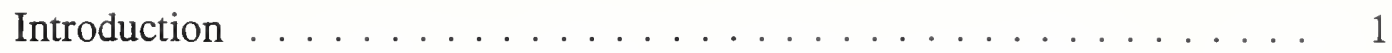

$1.1 \quad$ Background . . . . . . . . . . . . . . 1

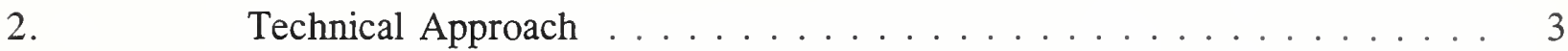

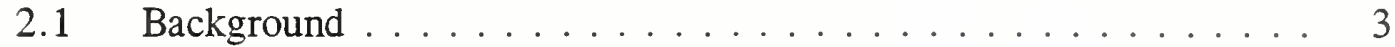

2.2.1 Questionnaire Survey ... . . . . . . . . . . 4

2.2.2 Physical Measurements .............. 4

3. Questionnaire Results . . . . . . . . . . . . . . . . . 9

3.1 General ........................ 9

3.2 Subjective Response to Lighting . . . . . . . . . . . . . 10

3.3 Thermal Environment . . . . . . . . . . . . . . . . . . . . 16

3.4 General Appearance of the Offices . . . . . . . . . . . 16

3.5 Reasons for Choices . . . . . . . . . . . . . . . . . . 19

4. Measurement Results . . . . . . . . . . . . . . . . 30

4.1 Lighting Measurements . . . . . . . . . . . . . . . . 30

4.2 Other Environmental Measures . . . . . . . . . . . . . . . . 39

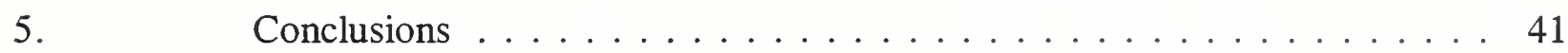

6. Recommendations for Completing Further Post Occupancy

Evaluations . . . . . . . . . . . . . . . . . . . 42

6.1 Determining the Sample Size and Composition . . . . . . . . 42

6.2 Suggested Questionnaire Contents . . . . . . . . . . . . . . 44

6.3 Suggested Physical Measurements . . . . . . . . . . . . . 45

6.4 Collecting and Analyzing the Data . . . . . . . . . . 45

Appendix A. Suggested Questionnaire Items . . . . . . . . . . . . . . . . . . . . . 49

Appendix B. Suggested Physical Measurement Form . . . . . . . . . . . . . . 55 
Figure 1. Ratings of the Quantity of Light as a Function of Sequence . . . . . . . 11

Figure 2. Ratings of the General Appearance of the Lighting System as a

Function of Sequence . . . . . . . . . . . . . . . 13

Figure 3. Ratings of Control of Light Sources as a Function of Window Orientation ........................ 14

Figure 4. Ratings of the General Amount of Space as a Function of Window Orientation ....................... 15

Figure 5. Ratings of the Thermal Environment as a Function of Window Orientation ...................... 17

Figure 6. Ratings of the Overall Appearance of the Office as a Function of Windows . . . . . . . . . . . . . . . . . . 18

Figure 7. Ratings of the Noisiness of the Space as a Function of

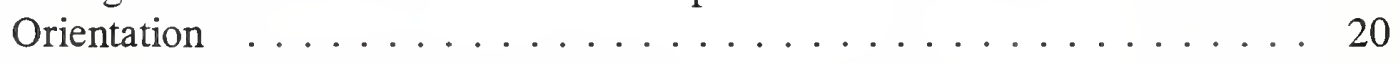

Figure 8. Percentage of Respondents for Choices . . . . . . . . . . . . 21

Figure 9. Distribution of Measured Illuminances at the Primary Work Station . . . . . . . . . . . . . . . . . . . 34

Figure 10. Mean Horizontal and Vertical Illuminance as a Function of Sequence. . . . . . . . . . . . . . . . . 35

Figure 11. Pattern of Lights and Luminance as a Function of Sequence. . . . . . . 37

Figure 12. Shifts in CIE x,y Coordinates for Color Samples as a Function of Sequence. . . . . . . . . . . . . . . . . 38

Figure 13. Measured Temperature and Humidity Data ... . . . . . . . . . 40

\section{List of Tables}

Table 1. Summary of Questionnaire Results for Sequence and Window Orientation ......................... 22

Table 2. Summary of Physical Measurement Data . . . . . . . . . . 31 


\section{$1.1 \quad$ Background}

Post-occupancy evaluation techniques provide a means for evaluating occupant responses to changes in an environment and linking this response to physical measures of that environment. Typically, post occupancy evaluations use a battery of tests to assess environmental conditions in the facility, including questionnaire surveys of the occupants, physical measures, personal observations, and individual interviews. The post-occupancy evaluation technique is thus designed to provide information about the occupants' reaction to their work spaces and document the physical conditions to which they are responding - usually on a pre- and post-retrofit basis.

Dillon and Vischer (1987a, b) used post-occupancy evaluation techniques to study four office buildings in Canada and develop response norms. Rubin and Collins (1987, 1988) and Collins and Rubin (1988) also used these techniques to evaluate environmental conditions in three U.S. Army field stations, while Marans (1987), Marans and Brown (1987), Gillette (1988), Gillette and Brown (1986), and Collins, Fisher, Gillette and Marans (1989) used them in a study of lighting, energy use, and other environmental conditions in thirteen office buildings in the United States. Each of these studies identified the importance of lighting, thermal comfort, indoor air quality and privacy as major factors in influencing human response to an environment.

Collins, Fisher, Gillette, and Marans (1990), Collins and Rubin (1988), Collins, Gillette, Dahir and Goodin (1989) presented data from post-occupancy evaluations of about 15 facilities in both government and private industry. These assessments provided information on physical conditions, especially lighting, and occupant reaction in the various buildings studied. Collins, et al, (1990) also found noticeable dissatisfaction with some lighting systems, particularly where fixed task lighting was combined with an indirect ambient lighting system. This particular system was associated with higher energy use (in terms of lighting power density) and higher illuminances, but lower ratings of lighting satisfaction than a comparable situation in which direct ambient lighting provided the primary illumination. Data from the post-occupancy evaluation of several U.S. Army facilities suggested that lighting levels were below IES minimum recommendations for the types of task performed in the facilities (Collins and Rubin, 1988; Collins et al, 1989). These two studies also found that occupant satisfaction was below that obtained in other areas in the same facility, probably because of the lower illuminances. Data from the Army facilities were used to suggest areas where lighting retrofits could be effective, as well as the types of office situations that could be improved.

Other studies have used only questionnaire or laboratory techniques to determine people's response to the environment. For example, a telephone survey by Louis Harris and Associates (Steelcase, 1987) questioned workers in the U.S. and Canada and found that respondents placed a great deal of emphasis on office layout, furniture, improved lighting, and chairs as the key to increasing productivity. These same respondents also placed considerable importance on 
privacy, improved temperatures, and reduced distractions or noise, as well as reduced glare on video display terminals (VDT) screens.

Laboratory studies of the response to lighted environments have identified lighting distribution as a key factor in determining occupant response to a space. For example, Flynn, Spencer, Martyniuk, and Hendrick (1973) found that ratings of perceptual clarity were dependent on the overall brightness of the space, while ratings of pleasantness depended on whether the peripheral room surfaces were lighted and whether the light was distributed uniformly throughout the space. Lighting installations identified as pleasant typically consisted of peripheral and non-uniform lighting, while spaces considered to appear spacious were lighted with a bright uniform distribution of light. Hawkes, Loe, and Rowlands (1979) determined that subjective brightness and interest were important factors in influencing the evaluation of lighting systems. In addition, the pattern of luminance was important: designs with only one wall lit were judged as dim, and designs using only diffuse sources were rated as less interesting than situations which used more focused sources. Hawkes, et al, suggested that situations that are judged as being brighter and more interesting (or complex) are also preferred. Recently, when Collins (1993) reviewed the literature on the psychological response to lighting, she found that, while enabling people to perform visual tasks, lighting also creates important perceptions, such as pleasantness, spaciousness, gloominess, and colorfulness. Finally, in a study of hospitals, Ulrich (1987) determined that windows provide important benefits, including speeding the recovery from illness to people in confined spaces, such as hospitals and even offices.

Not all environmental assessments have focused on lighting, however. Other studies have evaluated such environmental issues as thermal comfort, including temperature and humidity. For example the ASHRAE Standard (55-1981) states that: "80\% of all adults dressed for winter indoor conditions find temperatures acceptable between $68^{\circ} \mathrm{F}$ and $74.5^{\circ} \mathrm{F}\left(20-23.6^{\circ} \mathrm{C}\right)$, a relative humidity of $30-60 \%$, and the air velocity at 0.15 to $0.25 \mathrm{~m} / \mathrm{sec}$. Acceptable summer indoor temperature is between 73 and $79^{\circ} \mathrm{F}\left(22.8\right.$ to $\left.26.1^{\circ} \mathrm{C}\right)$. " Meyer $(1983$, p.27) pointed out the "extensive experimentation has shown that for an average, sedentary, lightly clothed person this [thermal comfort] occurs most readily when the air in a standard room has a temperature of 24.5 ${ }^{\circ} \mathrm{C}\left(76.1^{\circ} \mathrm{F}\right)$, a relative humidity of $40 \%$, and an air velocity of $0.25 \mathrm{~m} / \mathrm{sec}$." The IESNA provides recommendations for minimum illuminance levels, similar in concept to those that ASHRAE provides for thermal conditions. Thus, the IESNA (1993) suggests that a minimum of 500 lux is generally advisable for moderate to difficult visual tasks, although their recommendations are weighted by the age of the observer and the difficulty of the task itself. These recommendations do not address all the variables responsible for human response to a lighting environment, however, making it difficult to use a single number as a guide to the effectiveness of a particular lighting situation. 
As part of the Federal Relighting Initiative, the DOE Headquarters in Washington, D.C., was relighted during the summer of 1993 in a major effort to reduce the electricity consumption of the lighting system. Indeed, by retrofitting the lighting system in the Forrestal Building, DOE expects to reduce the electricity consumption of the lighting system by at least 60 percent. The projected energy savings are the result of retrofitting the old lighting system with new components. Prior to the retrofit, a portion of the luminaires in each office had been de-lamped as an energy savings measure creating an irregular and visually distracting pattern of energized luminaires. During the retrofit, the two T12 cool white fluorescent lamps (nominally 34-40 watts) and magnetic ballasts initially housed in each $30 \mathrm{~cm} \times 120 \mathrm{~cm}$ (1 ft. x $4 \mathrm{ft}$.) prismatic lensed luminaire were replaced by one T8 lamp and electronic ballasts. In addition, specular reflectors were added to increase the luminaire's optical efficiency. Although all luminaires were energized after the retrofit, the number of energized lamps per office actually decreased.

Collins, et al.(1990), Collins and Rubin (1988), Collins, et al.(1989) recently reported that employees were noticeably dissatisfied with the lighting in government facilities, especially where to save energy, lighting levels had been reduced below the minimum IES recommended illuminances. They concluded that, when lighting systems are retrofitted to conserve energy, it is critical to maintain, if not improve, the quality of the lighting. Since the current relighting initiative was intended to save energy, the present research was designed to assess its effect on the lighting quality in the building.

When lighting systems are retrofitted to conserve energy, it is critical to at least maintain, if not improve, the quality of the lighting. One of the most effective means for determining how the quality of the lighting changes as the result of a relighting effort is to ask the opinions of occupants of the lighted environment. The objective of the present research was to determine whether the relighting improved the overall lighting quality in the building and the occupant attitudes toward the lighting. A further objective was to measure the physical lighting characteristics before and after the retrofit. The overall energy consumption of the lighting system was evaluated by others, and so was outside the scope of this effort.

Post-occupancy evaluation techniques, including questionnaires and physical measurements, were used to evaluate the effectiveness of the relighting. These two techniques allow identification of relationships between subjective measurements of the environment provided by the occupants and objective physical measurements of the same spaces. Combined, they allow a determination of whether the changes made during the relighting improved both the physical conditions and the occupant response. Environmental conditions of concern in this study included lighting, temperature, general appearance, and presence/absence of windows. The occupant questionnaire addressed these areas, although it concentrated on response to the lighting. The physical measures concentrated on lighting - both task illuminance and room luminance - although supplementary measures were taken of VDT's and thermal conditions. 
A representative sample of 350 offices was selected for evaluation by DOE officials after consultation with NIST staff. This sample proportionately reflected the types of offices in the whole building based on their location within the building and presence of windows. The final sample included windowed and windowless offices (to assess any daylight contribution) from the basement to eighth floor, with windows facing North, South, East, and West. The sample included conventional as well as open-plan offices.

The two-part post-occupancy analysis was executed twice to collect the necessary data. The protocols for the questionnaire survey and the physical measures of the occupied spaces are described in the following sections (and presented in Appendix A). This analysis was first implemented in March 1993, before the relighting was initiated, and again in December 1993, two months after the relighting was completed.

\subsubsection{Questionnaire Survey}

The questionnaire survey was developed based on that used by Collins, et al, (1989) and Rubin and Collins (1988) for their evaluation of U.S. Army field stations but modified to focus in greater detail on the lighting. The three-part questionnaire generally covered respondent attitudes toward lighting, air quality, temperature, VDT's, space, noise, windows, facility appearance, and job satisfaction, as well as respondent's length of time at the facility and general demographic information. (The questionnaire is provided in Appendix A.) The first two parts of the questionnaire consisted of statements printed on a standard machine-readable form. The subjects responded by blackening the circles which represented their responses. In Part A, participants indicated the degree to which they agreed with the statements, and in Part B they rated the quality of particular environmental attributes. Part $\mathrm{C}$ allowed the subjects to provide additional written information which could not be easily collected using the machine-readable forms.

The questionnaire was distributed to the predetermined office spaces and included a business reply envelope in which the participants could return their completed forms. Although it was desirable to have paired data; that is, data from the same person before and after the relighting, this was not possible for two reasons. First, employees moved from one office to another during the course of the experiment and second, it was critical to maintain the anonymity of the participants. In spite of these restrictions, there was a concerted effort to ensure that the same offices were included in both questionnaire surveys. In this way it was possible to solicit responses from at least some of the same people. In fact, 30 percent of the participants in the post-retrofit survey volunteered that they had completed the same survey prior to the retrofit. Physical measurement data were collected from virtually the same offices.

\subsubsection{Physical Measurements}

Physical measurements were collected in March of 1993 (after the first questionnaire) and again in January, 1994 (after the second questionnaire). The physical data collection included a 
general space inventory as well as measures of lighting (both illuminance and luminance), temperature, and color. From these data, task contrast was calculated. The protocol used to collect these data is presented in Appendix B.

Prior to the retrofit, physical measures were made with hand-held instruments. The illuminance was measured at a number of locations within the space, using a Minolta ${ }^{1}$ photometer with a cosine-corrected diffuser and a photopic response filter. Illuminances were recorded for six locations on the main worksurface corresponding to a $3 \times 2$ grid. Vertical surface (wall) illuminances were measured at ten locations within each work space to characterize two horizontal bands on vertical surfaces within the space. The first band of five illuminances was measured approximately one meter above the floor and the second band was measured at a height of about 2 meters above the floor. Within each band five illuminances were measured, one to the immediate left and right of the observer seated at the desk, one straight ahead, and one approximately 45 degrees to the left and right of straight ahead. In addition, several illuminance measures were recorded to characterize the VDT work station. At the work station, the illuminance of the source document was recorded, as well as the illuminance of the keyboard and the VDT screen itself. The source document location was assumed to be to the left or right of the VDT and in a vertical or horizontal position as dictated by the presence of a document holder. The final illuminance recorded for each office was for a distinct position on the wall and was later used with luminance measures to calculate the reflectance of the paint used in the offices.

Luminances were measured using a Minolta Chromameter ${ }^{1}$ with a field of view subtending a visual angle of $1^{\circ}$ and calibrated to measure photopic luminances. Room surface luminances were recorded for a pattern similar to the previously described bands of illuminance measurements and from the viewing position of the office occupant (usually the seated position behind the desk). In addition, task luminance was measured for two "standard" tasks located both on the desk and at the position of the assumed source document location at the VDT workstation. One "standard" task was matte; the other was glossy in nature. The matte task was a white piece of paper with a black inked letterhead. The glossy task was a page from a magazine and consisted of a large area of white and a somewhat smaller area printed with black ink. Each task was placed at the near center of the desk and at the appropriate position at the VDT work station. The luminance of the white and black areas were recorded and later used to calculate the task contrast according to the following formula:

$1 \quad$ Brand names are given for the purposes of identification and do not constitute an endorsement by either the National Institute of Standards and Technology or the Department of Energy. 


$$
\mathrm{C}=\left(\mathrm{L}_{\mathrm{B}}-\mathrm{L}_{\mathrm{T}}\right) / \mathrm{L}_{\mathrm{B}}
$$

where:

$\mathrm{L}_{\mathrm{B}}=$ luminance of the background, and

$\mathrm{L}_{\mathrm{T}}=$ luminance of the target.

Luminances were also recorded for the brightest spot on the ceiling which was, invariably, an image of the lamp on the prismatic lens of a luminaire, and for the dimmest spot which was chosen to be at a location between luminaires. If there were windows, the luminances of the sky and of a nearby building were recorded. Lastly, the luminance of a distinct spot corresponding to the earlier described illuminance measurement was recorded to allow calculations of the reflectance of the painted walls.

Other measures recorded in each office included $\mathrm{CIE}^{2} \mathrm{x}, \mathrm{y}$ color coordinates for a single point on the wall as measured with the Chromameter; and temperature and relative humidity which were measured with a Solomat multi-channel modometer (2016) fitted with a platinum thermohygrometer.

After the retrofit, the same measures were recorded with a few modifications. To ease the data collection, a portable automated data collection device was used to collect most of the illuminance and luminance measures, as well as temperature and relative humidity. This collection device consisted of a 14 channel datalogger attached to a pole mounted on a wheeled base. Twelve photocells and a temperature and relative humidity probe were attached to the datalogger. Each of the photocells had a cosine-corrected diffuser and a photopic response filter. Eight of the photocells measured illuminance and four photocells measured luminance. Three of the four photocells used to measure luminance were identical to those used to measure illuminance except that a $2.6 \mathrm{~cm}$ tubular extension lined with black felt and having an inside diameter of about $2.2 \mathrm{~cm}$ was added to the front of the photocell to limit the viewing angle of the photocell to about $50^{\circ}$. Finally, the fourth photocell was calibrated for photopic viewing conditions and had a field of view of about $15^{\circ}$. It was mounted on a motorized turntable attached to the top of the pole at a height corresponding to seated eye level.

The twelve photocells were arranged in four different configurations. The first configuration was a folding " $\mathrm{X}$ " frame in which one illuminance probe was attached to each end. This configuration was used to measure the illuminance at four points on the worksurface. The second configuration consisted of a meter stick with an illuminance probe attached to either end. The third configuration was used to collect photometric information at the VDT workstation. It consisted of a rectangular frame which hung from the top edge of the VDT monitor. Attached to the frame were two illuminance probes and the three luminance probes fitted with the tubular

2 CIE stands for Commission Internationale de l'Eclairage or the International Lighting Commission which defines color in terms of $\mathrm{x}$ and $\mathrm{y}$ coordinates. 
extensions. The luminance probes were positioned to measure the luminance to the left, right and above the monitor. One illuminance probe was positioned to measure the illuminance on the VDT screen, while the final illuminance probe was used to measure the illuminance on the keyboard. In the fourth configuration, the final luminance probe was attached to a motorized horizontal turntable mounted at the top of the pole.

The datalogger was programmed to collect the data automatically in three different stages. In the first stage, the datalogger replaced the chair behind the desk and the folding " $\mathrm{X}$ " was placed on the worksurface. Upon launching the collection program, the four illuminances and temperature and relative humidity were recorded. In addition, the rotating luminance probe mounted to the top of the pole began a $180^{\circ}$ scan stopping every $45^{\circ}$ to measure the luminance of the surrounding surfaces. The first measure was recorded for a location immediately to the left of the position normally assumed by the employee seated at the desk, and subsequent measures were recorded for positions located in front of them. The second stage of the data collection involved holding the meter stick with the two illuminance probes in a vertical position with the lowest photocell one meter above the floor for each of the five positions described earlier. The third and final phase of the automated data collection involved hanging the rectangular frame containing the three luminance and two illuminance probes on the VDT monitor.

The datalogger stored the measurements as uncalibrated voltages in a storage module. At the end of each day, the data were uploaded onto a personal computer where it was later imported into a spreadsheet and converted to meaningful data by applying the appropriate calibration factors. The calibration factors for all of the probes were provided by the manufacturer assuming that the cells were to be used for illuminance measurements. However, since we configured the luminance probes in our laboratory, we also calibrated them using a standard luminance source. The standard source is an integrating sphere with a small opening in the wall and is internally illuminated by a fiber optic source. The luminance probes were mounted along the axis perpendicular to the opening in the sphere such that the opening of the tubular extension was aligned with the opening in the sphere. This ensured that the luminance probe was indeed exposed to a uniform luminance and that non-uniform areas were not included in the field of view.

In summary, then, the differences in measurement techniques and measurements before and after the retrofit can be described as follows: work surface illuminance was characterized by six measurements before the retrofit and four measurements after. Prior to the retrofit, room surface luminances were characterized by a series of ten measurements made with a luminance meter with a very small spot size $\left(1^{\circ}\right)$ while the post-retrofit room surface luminances were characterized by five wide angle measurements. Otherwise, the measurement procedures were similar for the two data sets.

Prior to the retrofit, physical measures were taken in a representative 100-office subsample of the 350 offices selected to receive questionnaire surveys. In this way the physical measures were recorded for offices from which questionnaire data were likely to be collected. This 
provided some assurance that the physical measures reflected the conditions actually experienced by the occupants. After the retrofit, physical measurements were taken in only 75 offices because virtually all of the renovated work stations throughout the building were identical.

In addition, since the spectral characteristics of the lamps changed from cool white before the retrofit to triphosphor after the retrofit, a set of color samples was measured before and after the retrofit to document the resulting color shifts. CIE x, y coordinates were measured with the Chromameter for a series of Munsell color chips found inside the back cover of the IESNA Handbook (Kaufman, 1972). The color measurements were recorded in three separate windowless offices before and after the retrofit. 


\section{$3.1 \quad$ General}

A total of 464 questionnaires were completed by Forrestal Building occupants, 244 before and 220 after the lighting system was retrofitted. Of the 220 respondents to the post-retrofit survey, 64 , or about 30 percent, also completed the survey prior to the retrofit. All participants ${ }^{3}$ engaged in typical office tasks including routine use of VDT's, paper tasks, phone and face-toface conversations.

The data for each questionnaire item collected before and after the retrofit were inspected for anomalies and analyzed using an analysis of variance (ANOVA) procedure with two dimensions: sequence - before and after the retrofit; and window orientation - north, south, east, west, and none. Since all levels of the window orientation factor did not have equal n's, as shown below, the particular ANOVA procedure chosen for the analysis assumed unequal sample sizes. In addition, statistical significance was based on an alpha of 0.05 . The results of the analysis are tabulated at the end of this section.

The number of respondents having a particular window orientation is shown below, with the percentage of respondents shown in parentheses.

\begin{tabular}{|c|c|c|c|}
\hline \multicolumn{2}{|l|}{ Before } & \multicolumn{2}{|c|}{ After } \\
\hline North 29 & (12 percent) & 27 & (12 percent) \\
\hline South 16 & (7 percent) & 14 & (6 percent) \\
\hline East 23 & (10 percent) & 21 & (10 percent) \\
\hline West & (7 percent) & 18 & (8 percent) \\
\hline None 155 & (65 percent) & 138 & (63 percent) \\
\hline
\end{tabular}

The statistical analysis of the data allows two important general observations. First, the items addressing lighting concerns were usually statistically significant when before and after retrofit conditions were compared (termed "sequence" in this report). Conversely, while non-lighting concerns were statistically significant for the window orientation factor, they were not for the sequence factor. This observation is fundamentally important because it suggests that the participants responded to the changes in the lighting system rather than to other environmental variables. Secondly, the statistically significant items regarding lighting showed a positive shift in response as a function of sequence. That is, occupants responded more favorably to the retrofitted lighting system than to the original system.

3 The participants' ages ranged from less than 20 years to more than 60 , with a median age of about 45 years. 
The figures and tables in section 3 summarize the questionnaire results in terms of the mean ratings given for selected questions. In the following sections, figures are presented for items which were statistically significant. The questionnaire items that were statistically significant for the window orientation factor were further analyzed to determine which means were different from the others using the Newman-Keules Multiple Comparisons technique for unequal number of participants and unequal variances (Howell, 1982). Questions for which no statistical significance was obtained are discussed in the text, and tabulated at the end of this section, but not presented graphically.

\subsection{Subjective Response to Lighting}

Figure 1 presents graphs containing the responses to three questions - amount of light to see clearly, dimness of the light, and overall amount of light - in terms of ratings of the quantity of light in the office before and after the retrofit. In this and subsequent figures, the black bar represents the mean ratings before the retrofit, while the gray bar depicts mean ratings after the retrofit. For these figures, ratings near 3 can be interpreted as neutral. All differences shown in the figures were statistically significant at or beyond $\mathrm{p} \leq .05$, according to the statistical analysis. The numeric data on which these conclusions are based are tabulated at the end of section 3. Inspection of the three graphs shown in figure 1 demonstrates that attitudes toward the lighting were significantly more positive following the retrofit. Occupants indicated that they could see more clearly, that the lighting was less dim, and that they had a greater overall amount of light. (Occupants disagreed that their lighting was too dim - a double negative which we interpret as meaning that they found their light to be sufficiently bright.)

Questions about quantity of light for which there was no significant change in the response were "the lighting in my office is too bright" with mean ratings ${ }^{4}$ of 3.78 before and 3.67 after, indicating that occupants somewhat disagreed with this statement; and "I am satisfied with the lighting in my work space" with mean ratings of 2.85 before and 2.65 after, indicating that occupants somewhat agreed with this statement. In both cases, occupants were slightly more positive after the retrofit about the lighting conditions in their offices (although not statistically significantly).

The difference between these two means is NOT significant for these data and for all subsequent presentation of means within the text in section 3 . 
Figure 1. Ratings of the Quantity of Light as a Function of Sequence

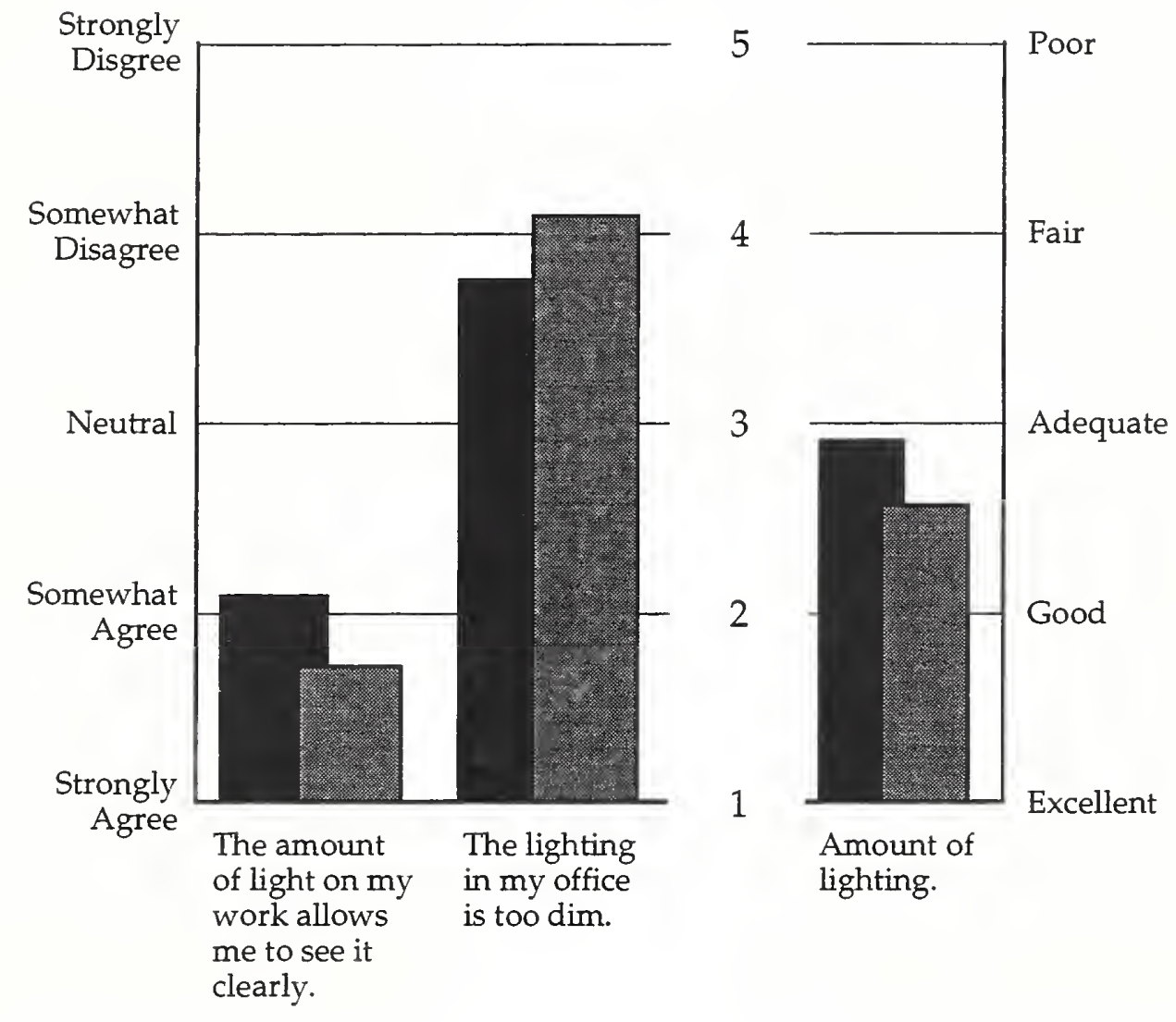

Legend

Before


Figure 2 presents data related to the appearance of the lighting system in the form of answers to six questions. The first four asked occupants to agree or disagree with a statement about their lighting, while the second two asked occupants to rate the appearance of the lighting on a five point scale. As can be seen in figure 2, occupants found their spaces to be less poorly lit, more pleasing, less glaring and the pattern of lights less bothersome after the retrofit. They also rated the appearance of their lighting system as better, along with the quality of the lighting.

In data not presented graphically but contained in table 1, occupants disagreed that the lights in their workstations made a loud buzzing noise, either before or after the retrofit (4.22 vs 4.46). Interestingly, they found no differences in the lighting of the conference rooms (2.97 vs 2.93) or restrooms ( 2.9 vs 3.06 ) - spaces that may not have been relamped at the time of the second questionnaire. They did, however, rate the relamped hallways as having better lighting quality (3.47 vs 3.10$)$.

Data for the four questions related to VDT's and presented in table 1 demonstrated no significant differences before and after retrofit. Thus, occupants did not find that their lighting washed out the computer display (mean 3.7) or created distracting reflections in the screen (mean 3.3). They also reported that their screens did not have anti-glare devices (mean 4.1), but that they could easily adjust screen brightness (2.11 vs. 1.98). They also reported no problem with shadows on their work because their body blocked the light (3.85) and they indicated that they could easily adjust their viewing distance to the screen (2.66 vs 2.7$)$.

Figure 3 presents data which show the effect of workstation orientation (north, south, east, and west or none). These data reinforce the importance of the window in determining occupant response. As noted earlier, the effect of the lighting retrofit sequence was not significant for these questions. Figure 3 indicates that occupants largely disagree with the idea that they would turn off some lights, although those in east-facing offices were more neutral on this question. All occupants, except those in west-facing offices, somewhat agreed with the idea of having an adjustable light on their desks. Occupants found no significant difference in the ability to adjust their lights with non-significantly different mean ratings of 4.35 before and 4.29 after.

In figure 4 , data for three questions reflect occupant attitudes toward their space, again as a function of their window orientation. The last bar of each set contains the responses of those in windowless offices - all of whom found their spaces more confining and less adequate for their jobs than those in offices with windows. Occupants in offices with windows also found the amount of space for their work to be better than did occupants of windowless offices (even though the amount of space was similar in both types of offices $-14.4 \mathrm{~m}^{2}$ vs about $12.6 \mathrm{~m}^{2}$ or $160 \mathrm{ft}^{2}$ vs about $140 \mathrm{ft}^{2}$ ). Occupants found their spaces to be somewhat more spacious after the retrofit (3.87 vs 3.64), but again this difference was not significant. 
Figure 2. Ratings of the General Appearance of the Lighting System as a Function of Sequence.

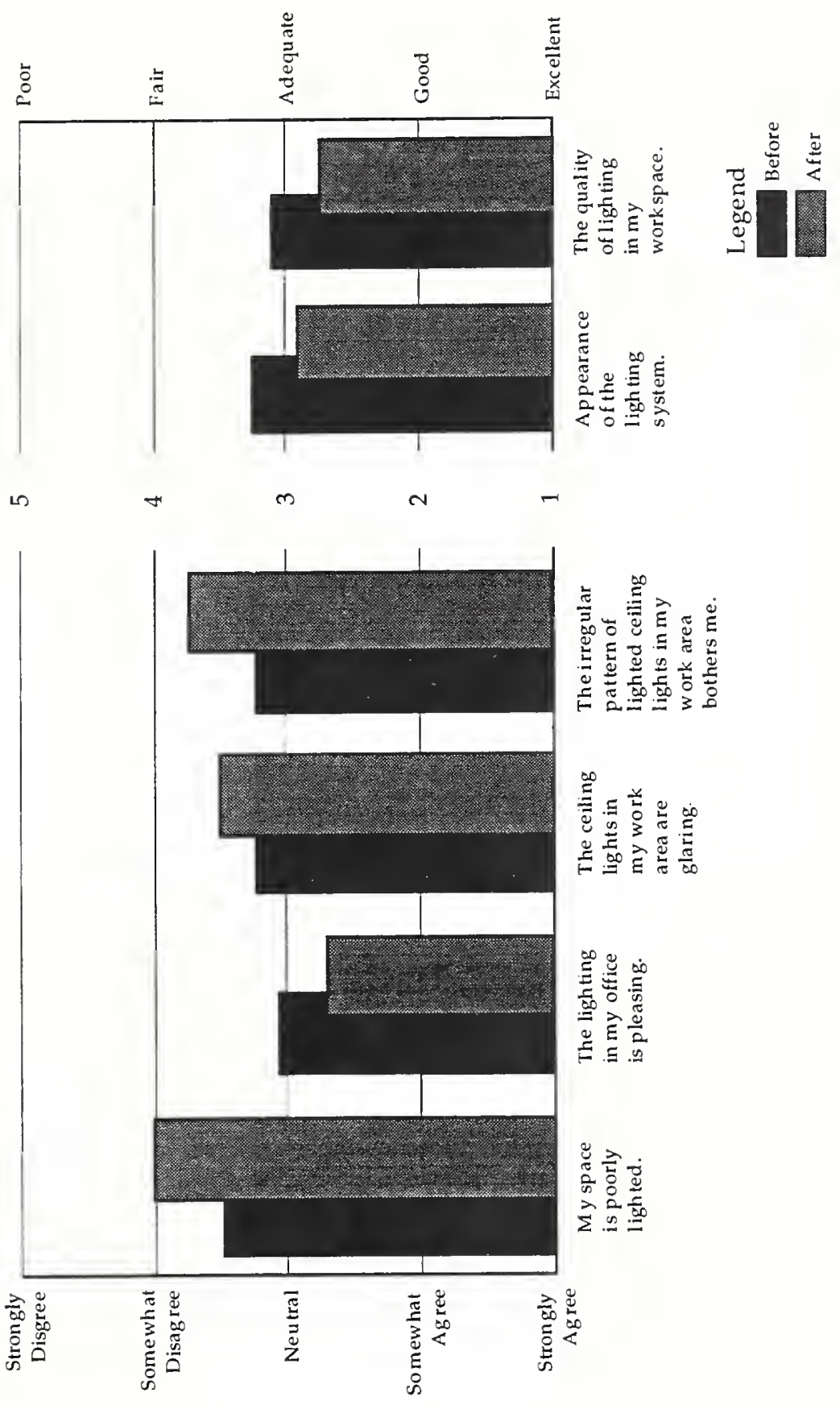


Figure 3. Ratings of Control of Light Sources as a Function of Window Orientation.

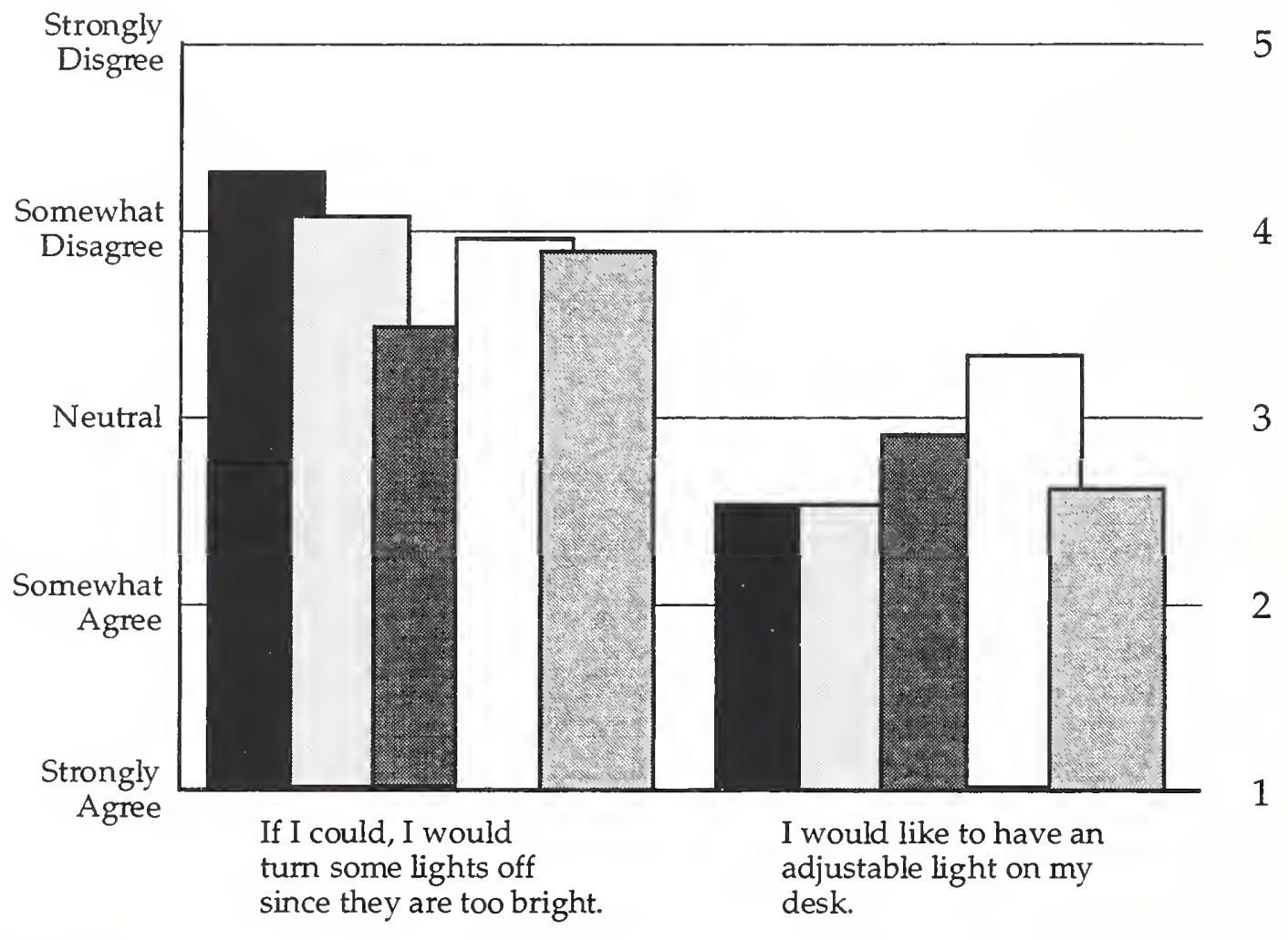

Legend

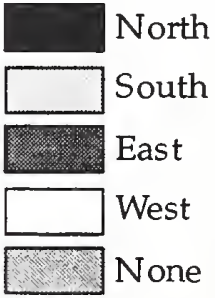


Figure 4. Ratings of the General Amount of Space as a Function of Window Orientation.
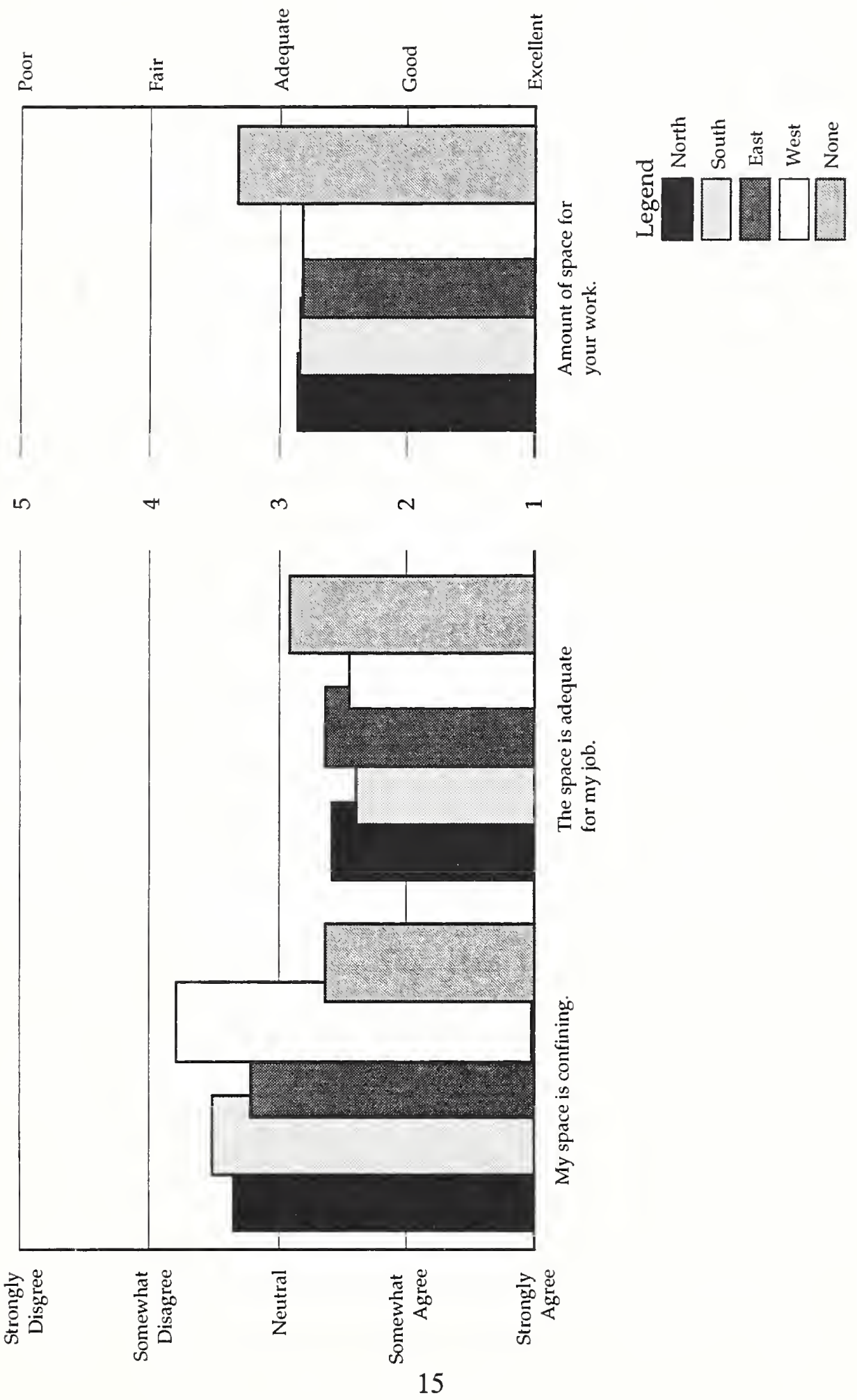
Figure 5 presents data related to the thermal environment. Again, the main effect is that of the window - rather than the lighting retrofit. Occupants in windowless offices generally found the air circulation to be less adequate, less humid, and hotter than occupants in other orientations, although there was a slight tendency for the approximately 15 people in the south-facing offices ${ }^{5}$ to find the air circulation to be less adequate, and hotter than occupants of other, windowed offices. Occupants generally rated the ventilation and air circulation to be adequate to fair again with those in windowless offices being somewhat less satisfied, closely followed by those in south-facing offices. Occupants did not find their offices to be too cold, as evidenced by almost identical mean ratings (3.3) before and after the retrofit, although they did find the room temperature to be only fair with ratings of 4.0 and 3.93 for the two questionnaires.

\subsection{General Appearance of the Offices}

Figure 6 presents data from four questions related to the general appearance of the space. Again the presence of a window showed the strongest effect. In general, occupants were relatively neutral to slightly negative about the overall appearance of their offices. Those in windowless offices found the overall appearance of their offices to be less pleasing; were slightly less satisfied with their work spaces; and found them to be less colorful and less stimulating than occupants in windowed offices.

For the questions about office appearance, the biggest effect is shown by the "windowless" conditions, with much less difference between the various window orientations. These data suggest that the presence of a window played the biggest role in determining occupant response to the general appearance of their offices. When sequence effects are considered, no significant differences emerge in attitudes toward the colors in the offices, with occupants rating the "naturalness" of their colors as 2.7 before and after the lighting retrofit, and the color of furniture and objects as 3.4 before and after. There was also no significant difference in the appearance of the space before and after (mean ratings of 3.5). They also believed that they had enough space to perform their job, again with no significant difference between retrofit conditions ( 2.49 vs 2.51 ). The spaces were rated as being somewhat less than pleasant with no change between retrofit conditions (3.59 vs 3.55 ). solar radiation. 
Figure 5. Ratings of the Thermal Environment as a Function of Window Orientation.
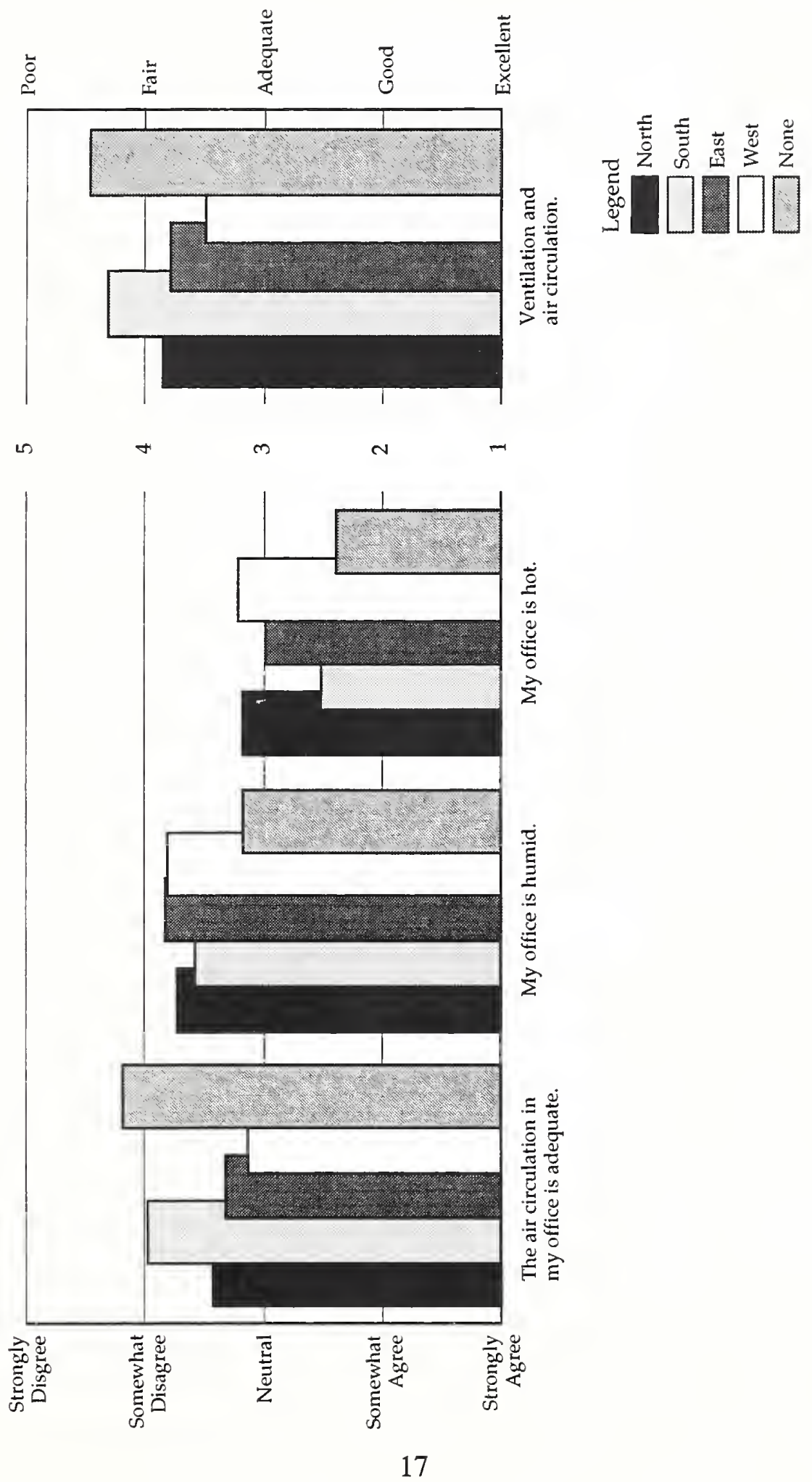
Figure 6. Ratings of the Overall Appearance of the Office as a Function of Window Orientation.

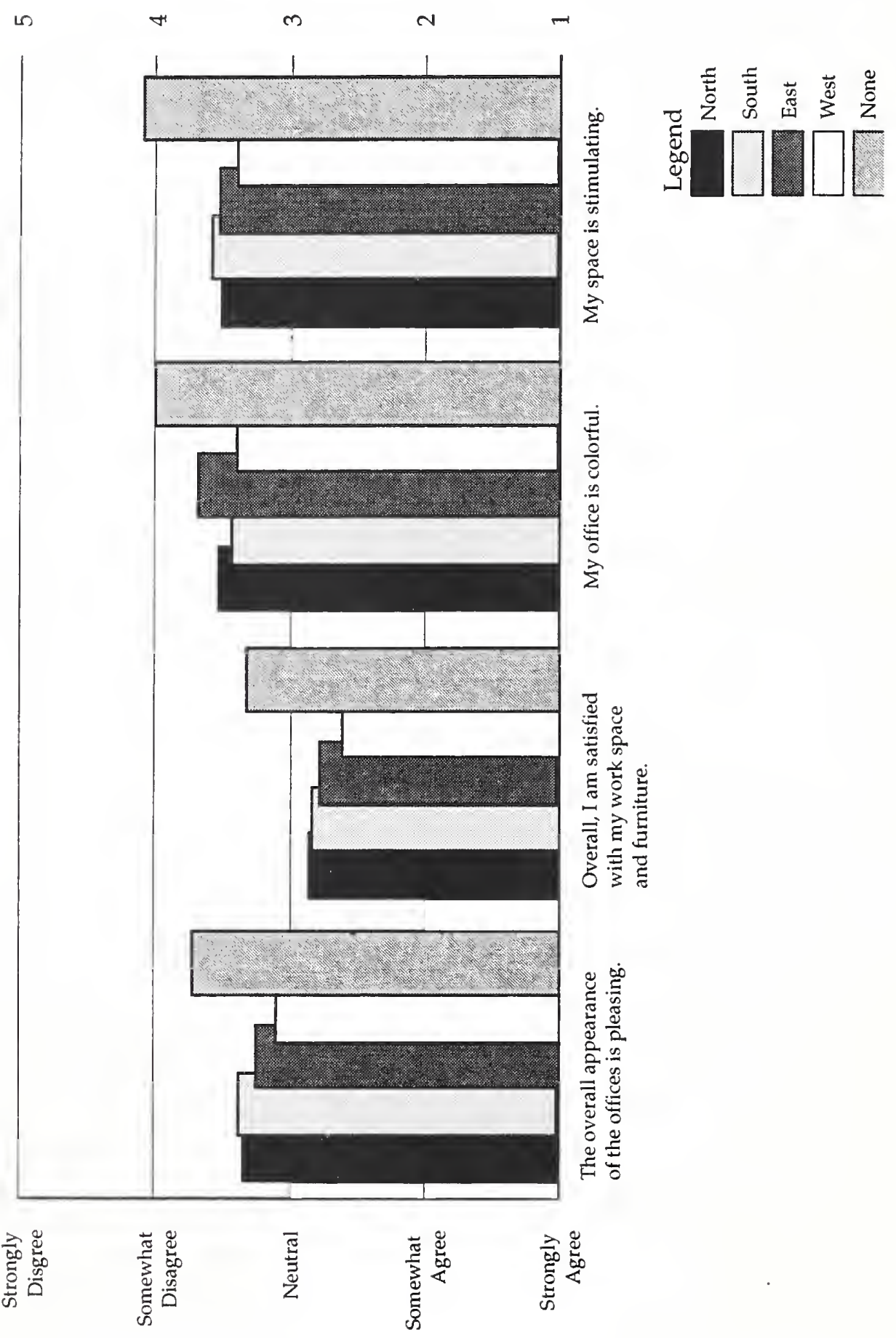


Figure 7 presents data on the attitudes toward noisiness of the office space. Occupants of southfacing offices found them to be somewhat noisy, while those in windowless offices found them to be less noisy. Occupants generally agreed that they had reasonable conversational privacy with no significant differences in their ratings for this question (3.63 vs 3.69) between conditions, and did not feel that noise kept them from doing their job well (3.26 vs 3.14). Occupants also reported no significant differences in the condition of their desks and chairs (3.0 vs 3.15); maintenance of the space (3.35 vs 3.51); and cleanliness of the space (3.19 vs 3.41).

Three questions about general morale indicated that the participants had very positive attitudes toward their work, with no significant differences between the relighting conditions or window conditions. Respondents clearly believed that their work was important to the operations of their office (1.62 vs 1.56); were satisfied with the quality of their work (1.74 vs 1.78$)$; and generally disagreed with the idea that the work atmosphere was tense (2.87 vs 2.99$)$. These data are among the most positive contained here, indicating no adverse effects of the relamping.

Table 1 summarizes the results of the statistical analysis for all the questionnaire data. This analysis was based on a two-factor Analysis of Variance for each question where the two factors were sequence (Before vs After) and window orientation (North, South, East, West, and None). The first part of the table, Part A, summarizes those items that were statistically significant for the sequence factor - implying that the differences in participant responses between retrofit conditions were not due to chance. The last column provides a descriptive statement about the basic trend of the data. The second part of the table, Part B, reports the items that were significant for window orientation. The means were later analyzed with a Newman-Keules Multiple Comparisons test based on unequal n's and unequal variances (Howell, 1982) to test which means were statistically different from the others. The means that share a common underline are statistically the same but different from those which do not share the same underline. The third part of the table, Part $\mathrm{C}$, lists the items that were not statistically different along any factor. For these items, the Grand Mean \pm 1 standard error of the mean is reported. Part D, the last part of the table, lists those items that exhibit an interaction between the two factors. In Table 1 each item includes a code in the left-hand column which indicates the type of response requested of the occupant. This code correlates the verbal response to the reported numerical ratings which are included at the top of Table 1.

\subsection{Reasons for Choices}

Occupants were also asked to indicate which four aspects of their offices that they would change if they could. Figure 8 summarizes the data from before and after the retrofit in a stacked bargraph format. In this graph, the choice is presented along the abscissa, while the percentage of respondents who selected that choice is presented for each of the four possible choices. Figure 8 indicates very clearly that the most desired choices were "more comfortable day-to-day temperatures"; "improved air circulation"; and "view out/daylight" with relatively little change between retrofit conditions. The only change between retrofit conditions occurred for "improved lighting" which was selected much less frequently after the retrofit, demonstrating that the relighting had achieved one of its goals. 
Figure 7. Ratings of the Noisiness of the Space as a Function of Window Orientation.
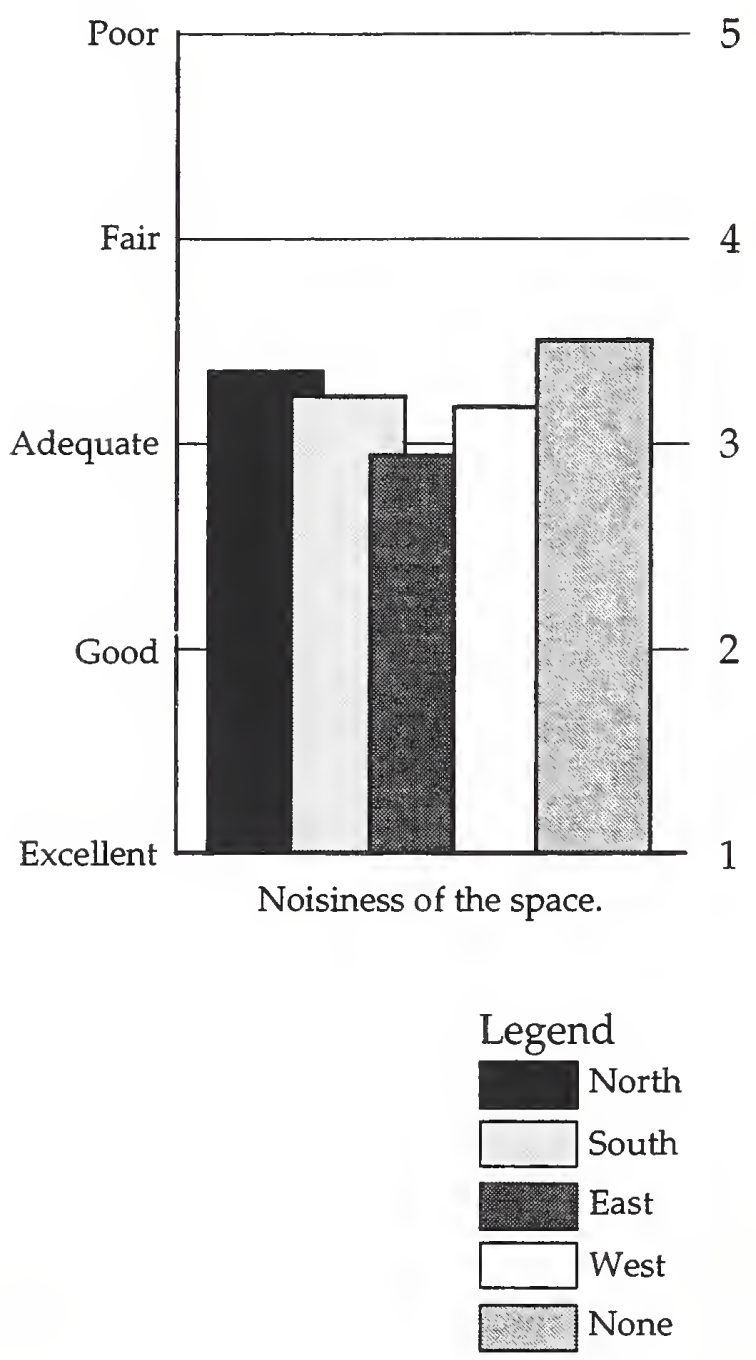
Figure 8. The Percentage of Respondents That Chose the Proposed Hypothetical Changes to Their Office

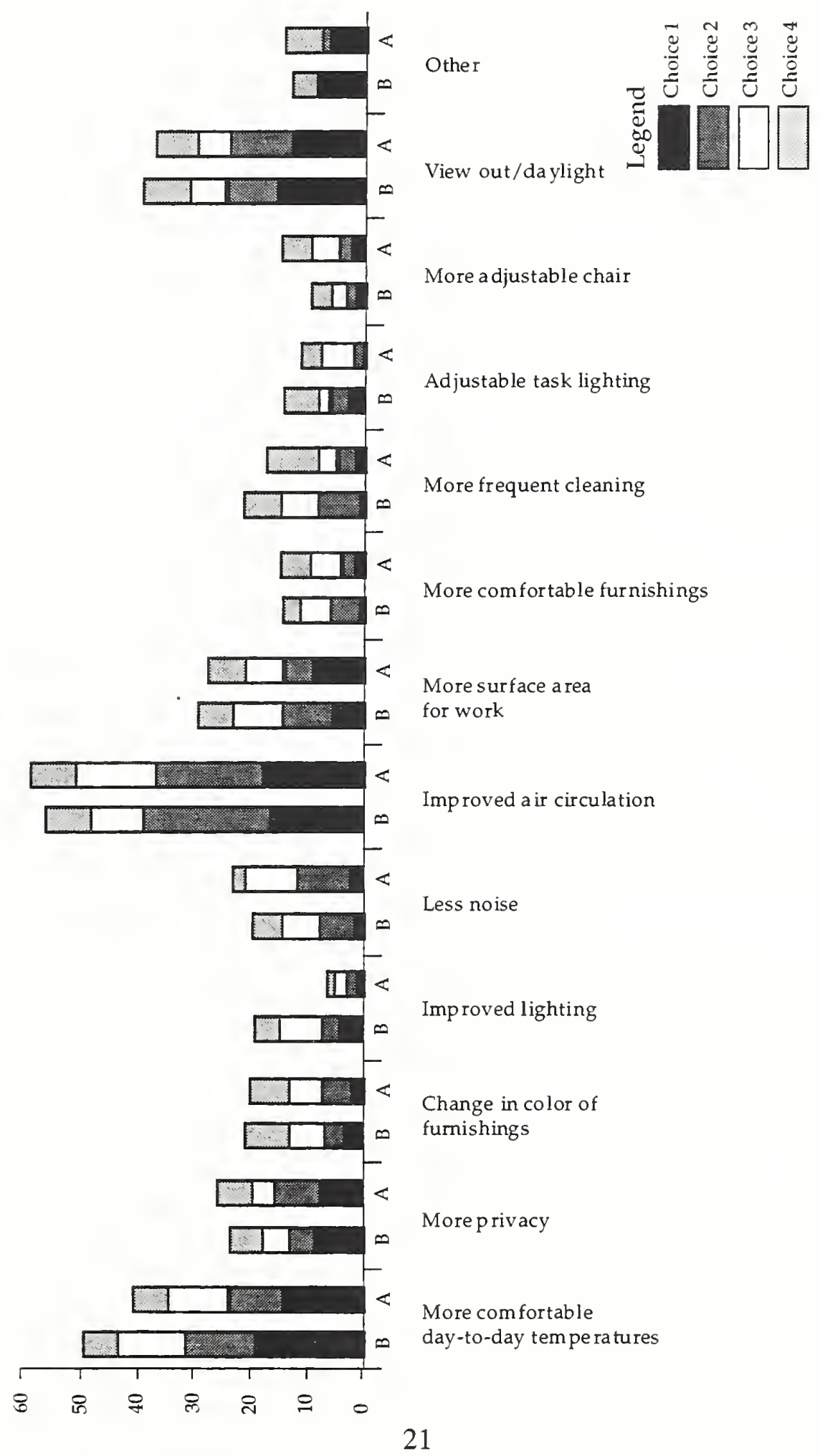


Table 1. Summary of Questionnaire Results for Sequence and Window Orientation \begin{tabular}{llllll} 
& \multicolumn{9}{c}{ Scale } \\
\cline { 2 - 5 } Item Code & 1 & 2 & 3 & 4 & 5
\end{tabular} Strongly Somewhat Somewhat Strongly
A:
Agree
Agree
Neutral
Disagree
Disagree

B:

Excellent

Good

Adequate

Fair

Poor

PART A: Items that are statistically different for the Sequence Factor.

Code Question

A The amount of light on my work allows me to see it clearly.

A The ceiling lights in my work area are glaring

A The light in my office is pleasing

A The irregular pattern of lighted ceiling lights bothers me

A My space is poorly lighted

A The lighting in my office is too dim

\section{Mean Mean Difference $p$}

Before After in Means value Trend

$\begin{array}{lllll}2.11 & 1.73 & 0.38 & 0.00 & \begin{array}{l}\text { Better } \\ \text { after }\end{array}\end{array}$

3.26

3.54

$-0.29$

0.02 Less

glare

after

3.08

2.73

0.35

0.00

Better

after

3.26

3.76

$-0.50$

0.00

Less bothersome after

4.03

$-0.52$

0.00

Better

lighting

after

3.76

4.10

$-0.34$

0.00

Brighter after 

B Amount of lighting
2.90
2.57
0.33
0.00 Better
amounts
after
B The quality of the
3.47
3.10
0.37
0.00
Better after
lighting in the corridors
B The quality of the light
3.14
2.79
0.35
0.00
Better in my work space
quality
after

PART B: Items that are statistically significant for the Window Orientation Factor:

A I would turn some lights off since they are too bright

\begin{tabular}{ccccc} 
East & None & West & South & North \\
3.49 & 3.90 & 3.97 & 4.07 & 4.32 \\
& & & \\
\hline
\end{tabular}

General disagreement implying not enough light.

A I would like to have an adjustable light on my desk

\begin{tabular}{ccccc} 
South & North & None & East & West \\
2.53 & 2.54 & 2.62 & 2.91 & 3.32 \\
& & & \\
\hline
\end{tabular}

General agreement although East and West exposures less.

A My space is confining

\begin{tabular}{ccccc} 
None & East & North & South & West \\
2.65 & 3.25 & 3.36 & 3.53 & 3.82 \\
& & & \\
\hline
\end{tabular}

General agreement with those having windows agreeing less 
A The space is adequate for my job

$\begin{array}{ccccc}\text { South } & \text { West } & \text { North } & \text { East } & \text { None } \\ 2.41 & 2.47 & 2.61 & 2.66 & 2.94\end{array}$

Generally agreeable (None - windowless - less agreeable)

B Amount of space for your work

$\begin{array}{llccc}\text { East } & \text { West } & \text { North } & \text { South } & \text { None } \\ 2.84 & 2.85 & 2.87 & 2.88 & 3.34\end{array}$

Generally Good, with Windowless Adequate to Fair

A The air circulation in my office is adequate

$\begin{array}{lcccc}\text { West } & \text { East } & \text { North } & \text { South } & \text { None } \\ 3.15 & 3.34 & 3.45 & 4.00 & 4.23\end{array}$

General disagreement. South and None disagree more strongly.

A My office is humid

\begin{tabular}{ccccc} 
None & South & North & East & West \\
3.20 & 3.60 & 3.75 & 3.86 & 3.85 \\
& & & & \\
\hline
\end{tabular}

Generally disagree though $S$ and None were more agreeable 
A $\quad$ My office is hot

\begin{tabular}{ccccc} 
None & South & East & North & West \\
2.42 & 2.53 & 3.02 & 3.20 & 3.25 \\
& & & & \\
\hline
\end{tabular}

Generally agreeable especially for South and None

B Ventilation and air circulation

$\begin{array}{lcccc}\text { West } & \text { East } & \text { North } & \text { South } & \text { None } \\ 3.53 & 3.82 & 3.88 & 4.33 & 4.48\end{array}$

West, East, North adequate to fair; South and None fair to poor

A The overall appearance of offices is pleasing

$\begin{array}{llccc}\text { West } & \text { East } & \text { North } & \text { South } & \text { None } \\ 3.12 & 3.27 & 3.36 & 3.40 & 3.74\end{array}$

General disagreement though those with windows were more pleased.

A My office is colorful

$\begin{array}{lcccc}\text { West } & \text { South } & \text { North } & \text { East } & \text { None } \\ 3.41 & 3.47 & 3.55 & 3.70 & 4.03\end{array}$

General disagreement though those with windows were more agreeable 
A Overall I like my work space and furniture

$\begin{array}{lcccc}\text { West } & \text { East } & \text { North } & \text { South } & \text { None } \\ 2.64 & 2.80 & 2.87 & 2.88 & 3.35\end{array}$

General agreement with exception of those without windows

A $\quad$ My space is stimulating

$\begin{array}{lcccc}\text { West } & \text { North } & \text { East } & \text { South } & \text { None } \\ 3.42 & 3.53 & 3.55 & 3.60 & 4.12\end{array}$

General disagreement though windowless greater disagreement

B Noisiness of the space

\begin{tabular}{lcccc} 
East & West & South & North & None \\
2.95 & 3.18 & 3.23 & 3.35 & 3.51 \\
\hline
\end{tabular}

East good to adequate, others adequate to fair

B How many hours do you work at a VDT per day

\begin{tabular}{ccccc}
$\begin{array}{cccc}\text { North } \\
2.05\end{array}$ & East & South & West & None \\
& 2.40 & 2.50 & 2.56 & 2.69 \\
\hline
\end{tabular}

Those with windows less likely to work at computers 
B How many hours do you spend reading and writing

$\begin{array}{lcccc}\text { West } & \text { None } & \text { East } & \text { North } & \text { South } \\ 2.71 & 2.77 & 2.79 & 3.20 & 3.20\end{array}$

North, South windows more likely to spend more hours reading and writing.

PART C: Items that are not statistically significant for any Factor. Grand Means \pm 1 SEM is reported.

A I create shadows on my work because of my body

$$
3.85 \pm 0.059 \text { Disagree }
$$

A The lighting in my office is too bright

$3.73 \pm 0.06$ Disagree

A I am satisfied with the lighting in my work space

$2.74 \pm 0.06$ Neutral to Agree

B Ability to adjust light for work

$4.33 \pm 0.05$ Fair to Poor

A The amount of light in my office washes out the VDT

$3.74 \pm 0.05$ Disagree

A Ceiling lights create distracting reflections in my VDT

$3.38 \pm 0.06$ Nentral to Disagree

A My computer has an antiglare device

$4.12 \pm 0.06$ Disagree

A I can easily adjust the brightness of my VDT

$2.04 \pm 0.05$ Agree

A The colors in my office appear natural

$2.78 \pm 0.056$ Agree to Neutral

B Color of furniture and objects

$3.44 \pm 0.05$ Adequate to Fair 
A $\quad$ My space appears spacious

$3.76 \pm 0.06$ Disagree

B The appearance of the workspaces and offices

$3.55 \pm 0.05$ Adequate to Fair

B Maintenance of the space

$3.43 \pm 0.05$ Adequate to Fair

B Condition of desks and chairs

$3.08 \pm 0.05$ Neutral

A My work is important to the functioning of this office $1.59 \pm 0.43$ Agree

A I am satisfied with the quality of my work

$1.77 \pm 0.04$ Agree

A The work atmosphere in my office is tense

$2.93 \pm 0.06$ Neutral

A My office is cold

$3.32 \pm 0.06$ Neutral to Disagree

A The lights in my work area make a loud humming sound $4.35 \pm 0.05$ Disagree

B The quality of lighting in conference rooms

$2.96 \pm 0.05$ Neutral

B The quality of lighting in the restrooms

$3.02 \pm 0.05$ Neutral

B Conversational privacy

$3.66 \pm 0.06$ Adequate to Fair 
B Cleanliness of the space

$3.30 \pm 0.05$ Adequate to Fair

PART D: Items that show an interaction between the two factors:
A I have enough space to perform my job
A $\quad$ Noise keeps me from doing my job well
A I can easily adjust my viewing distance to the VDT
B Pleasantness of the space
B Room temperature

INTERACTION

INTERACTION

INTERACTION

INTERACTION

INTERACTION 


\subsection{Lighting Measurements}

Using a procedure similar to that given in Appendix B, a total of 100 work stations were examined before and 75 after the relighting. All the physical measurement data recorded for each office were entered into a spreadsheet for easy manipulation. A number of summary measures, such as task contrast, mean worksurface illuminance, and mean wall luminance, were created. These data were analyzed similarly to those presented for the questionnaire results, using a twofactor analysis of variance assuming unequal sample sizes and variance. As in that analysis, the two factors were sequence and window orientation. The results are presented in Table 2.

As with the questionnaire analysis, the following figures present the measurement data that were significant for the sequence or window factors. Figure 9 presents the distribution of illuminance at the primary work station for five measurement points located at two distances ( $1 \mathrm{~m}$ and $2 \mathrm{~m}$ ) above the floor before and after the relighting. The upper portion of figure 9, 9a, presents illuminance data for all offices; while the lower portion, $9 \mathrm{~b}$, presents data only for windowless offices. Inspection of the open diamonds in figure $9 \mathrm{a}$ indicates clearly that illuminance was greater after the relighting than before. The increase was greatest for measurement points located $2 \mathrm{~m}$ above the floor - which went from about 290 lux to about 450 lux after the relighting. A similar change can be seen in figure $9 \mathrm{~b}$, where the illuminance for points located $2 \mathrm{~m}$ above the floor increased significantly after the relighting. These shifts indicate that there was little luminance gradient within the offices before the relamping - meaning that the upper portion of an office had relatively less luminance than desirable. Figure $9 \mathrm{~b}$ also provides an indication of the role of daylight in the overall illuminance in the offices since the $2 \mathrm{~m}$ measures increased only to 400 lux for windowless offices after the retrofit as compared with 450 lux for all offices.

Figure 10a presents data for mean horizontal illuminance on the workplane before and after the retrofit. Before data are shown in black and after in gray. Figure 10a further separates the data into categories according to window orientation. The central line at 500 lux was the target minimum value desired by DOE for the relighting. This figure indicates clearly that east-facing and windowless offices had levels below the target minimum maintained horizontal illuminance before the relighting. All offices had levels above this target minimum following the relighting, although the level was lowest for offices with no windows. In addition, after the retrofit, offices with windows had mean horizontal illuminance at or above 650 lux; that for the windowless offices was about 550 lux. Figure $10 \mathrm{~b}$ presents mean vertical illuminance on the wall for all offices, before and after the retrofit. This figure summarizes the data for all windowed conditions and orientations. It confirms that wall illuminance increased significantly following the retrofit, with an increase from about 260 lux to about 340 lux - for all offices. 
Table 2. Summary of Physical Measurement Data

PART A: Items that were statistically significant for the Sequence Factor.

Measurement

Mean standard deviation of wall

illuminances in each office

Mean CIE y-coordinate for office walls

Mean luminance of darkest spot

on ceiling $\left(\mathrm{cd} / \mathrm{m}^{2}\right)$

Mean luminance of brightest spot on ceiling $\left(\mathrm{cd} / \mathrm{m}^{2}\right)$

Average wall illuminance (lux)

Number of lamps per square meter

Relative Humidity (percent)

Mean file length

$\begin{array}{llc}\text { Mean } & \text { Mean } & \mathrm{p} \\ \text { Before } & \text { After } & \text { value }\end{array}$

74

108

0.01

0.425

0.413

0.00

40.6

47.1

0.03

3094

4712

0.01

269

339

0.04

0.69

0.42

0.01

28

14

0.00

0.94

10.1

0.00

PART B: Items that were statistically significant for the Window Orientation Factor:

Source document illuminance (lux)

$\begin{array}{ccccc}\text { None } & \text { East } & \text { South } & \text { West } & \text { North } \\ 385 & 523 & 531 & 603 & 691\end{array}$


Luminance ratio of brightest spot to dimmest spot on ceiling $\left(\mathrm{cd} / \mathrm{m}^{2}\right)$

North

62
West

85
South

88
East

92
None

104

Mean work surface illuminance (lux)

$\begin{array}{ccccc}\text { None } & \text { East } & \text { South } & \text { West } & \text { North } \\ 491 & 537 & 602 & 654 & 719\end{array}$

PART C: Items that are not statistically significant for any Factor. Grand Means \pm 1 SEM are reported.

Mean background luminance of matte paper task (white)

$196.5 \pm 46.5\left(\mathrm{~cd} / \mathrm{m}^{2}\right)$

Mean task luminance of matte paper task (black)

$22.4 \pm 3.3\left(\mathrm{~cd} / \mathrm{m}^{2}\right)$

Mean task contrast of matte paper task

$0.87 \pm 0.01$

Mean background luminance of glossy paper task (white)

$184.7 \pm 47.5\left(\mathrm{~cd} / \mathrm{m}^{2}\right)$

Mean task luminance of glossy paper task (black)

$19.0 \pm 6.6\left(\mathrm{~cd} / \mathrm{m}^{2}\right)$

Mean task contrast of glossy paper task

$0.91 \pm 0.01$

Mean CIE x-coordinate for office walls (color)

$0.418 \pm 0.001$

Mean office area

$13.3 \pm 0.37 \mathrm{~m}^{2}$ 
Mean desk area

$1.4 \pm 0.02 \mathrm{~m}^{2}$

Mean reflectance of office walls ( $r h o$ )

$0.77 \pm 0.004$

\section{PART D: Summary Descriptive Statistics}

Before After

Percentage of offices with computers

97

97

Percentage of computers with adjustable screens

96

99

Source document location

Left of computer horizontal

Left of computer vertical

Right of computer vertical

Right of computer horizontal

Percentage of "Open Plan" Offices

Percentage of offices having stated number of occupants

One
Two
Three
Four

Percentage of offices with pictures or posters

$87 \quad 95$

Percentage of offices with personal effects on the desk $\quad 77 \quad 93$

$\begin{array}{lll}\text { Percentage of offices with personal fans } & 35 & 37\end{array}$

Percentage of offices with space heaters

33 
Figure 9. Distribution of Measured Wall Illuminances as a Function of the Presence of a Window in the Office.

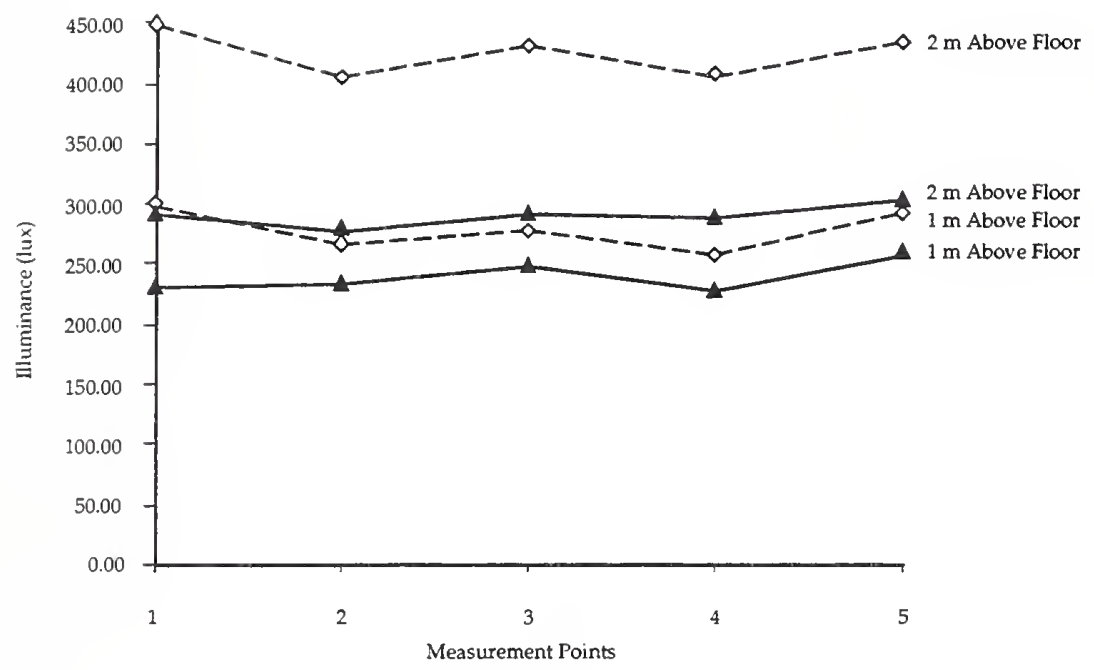

9a. Illuminance Distribution in All Offices

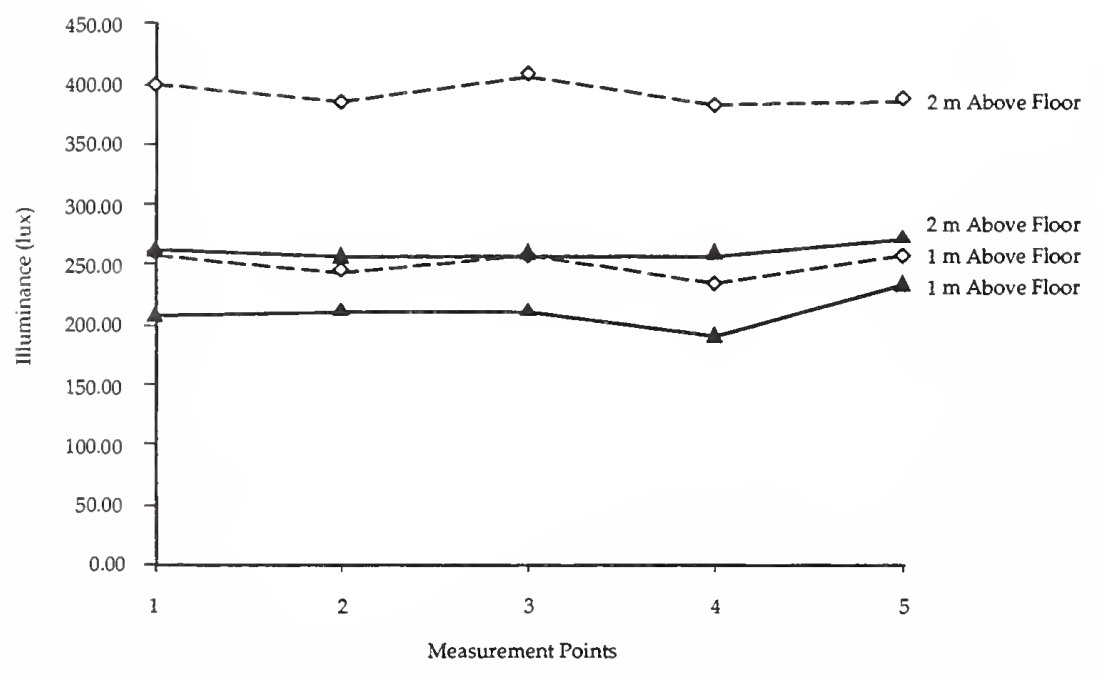

Legend

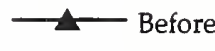

$-\diamond--$ After

9b. Illuminance Distribution in Windowless Offices 
Figure 10. Mean Horizontal Illuminance as a Function of Window Orientation and Sequence and Mean Vertical Illuminance on the Wall as Function of Sequence.

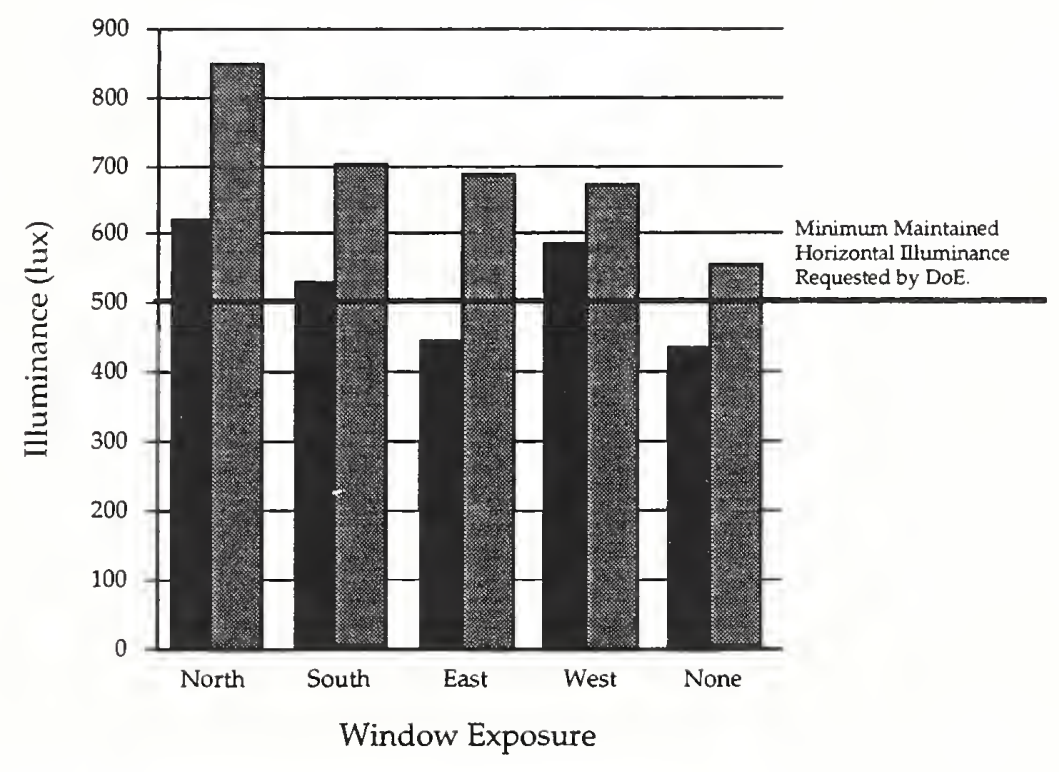

10 a. Mean Horizontal Illuminance on the Workplane

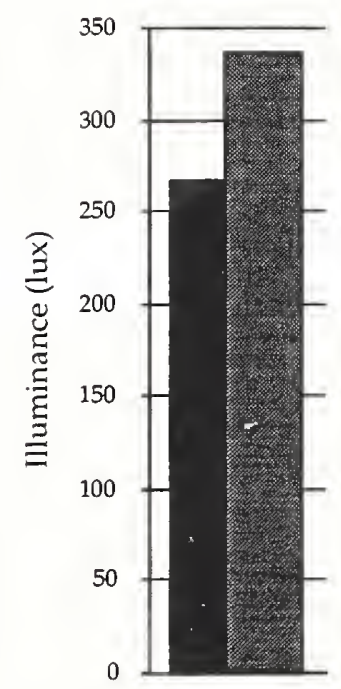

Legend

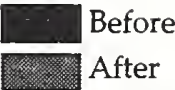

$10 \mathrm{~b}$. Mean Vertical Illuminance on the Wall for all Offices Before and After the Retrofit. 
Figure 11 describes the pattern of lamps and luminances in the offices before and after the relighting. Figure $11 \mathrm{a}$, which presents the mean density of lamps, indicates that there were fewer lamps per square meter after the relighting than before. Figure $11 \mathrm{~b}$ amplifies these data by indicating that, although there were fewer lamps energized, these lamps were located in a far greater percentage of luminaires. Before the relighting only about 72 percent of the luminaires were energized; after, almost all (about 98 percent) the luminaires were energized. Before the relighting, many of the two-lamp luminaires had been delamped. After, each luminaire had one energized lamp. This change to a greater number of energized luminaires meant that the "patchwork" appearance of the ceiling - with a few very bright luminaires contrasting with some very dark (unlit) areas - was lessened. Figure 11c indicates that the mean luminance of the brightest spot on the ceiling increased significantly - from about 3000 $\mathrm{cd} / \mathrm{m}^{2}$ to about $4600 \mathrm{~cd} / \mathrm{m}^{2}$. This was likely due to the higher lumen output of the new lamp compared to the old and the fact that the brightest spot on the ceiling was the image of the lamp through the prismatic lens of the luminaire. In addition, fixtures were cleaned during the relighting which would also have increased their overall brightness. Finally, figure $11 \mathrm{~d}$ presents the mean ratio of highest ceiling luminance to lowest, which also increased after the relighting, again reflecting that the lamp images were brighter. Consideration of the four graphs in figure 11 suggests that the pattern of luminances in the office had become more regular and that the upper walls and ceiling had become generally brighter after the relighting.

Figure 12 presents CIE x,y coordinates for color samples measured before and after the retrofit. The set of color samples, used to approximate interior accent colors, were Munsell color chips from the IESNA Handbook (1972). Figure 12 indicates that the gamut of colors (Boyce, 1977) had increased after the retrofit, particularly in the red-purple range. The change from cool white to T-8 triphosphor lamps (with higher color rendering and color temperature) would account for this increased gamut of colors. 
Figure 11. Pattern of Lights and Luminance as Function of Sequence.
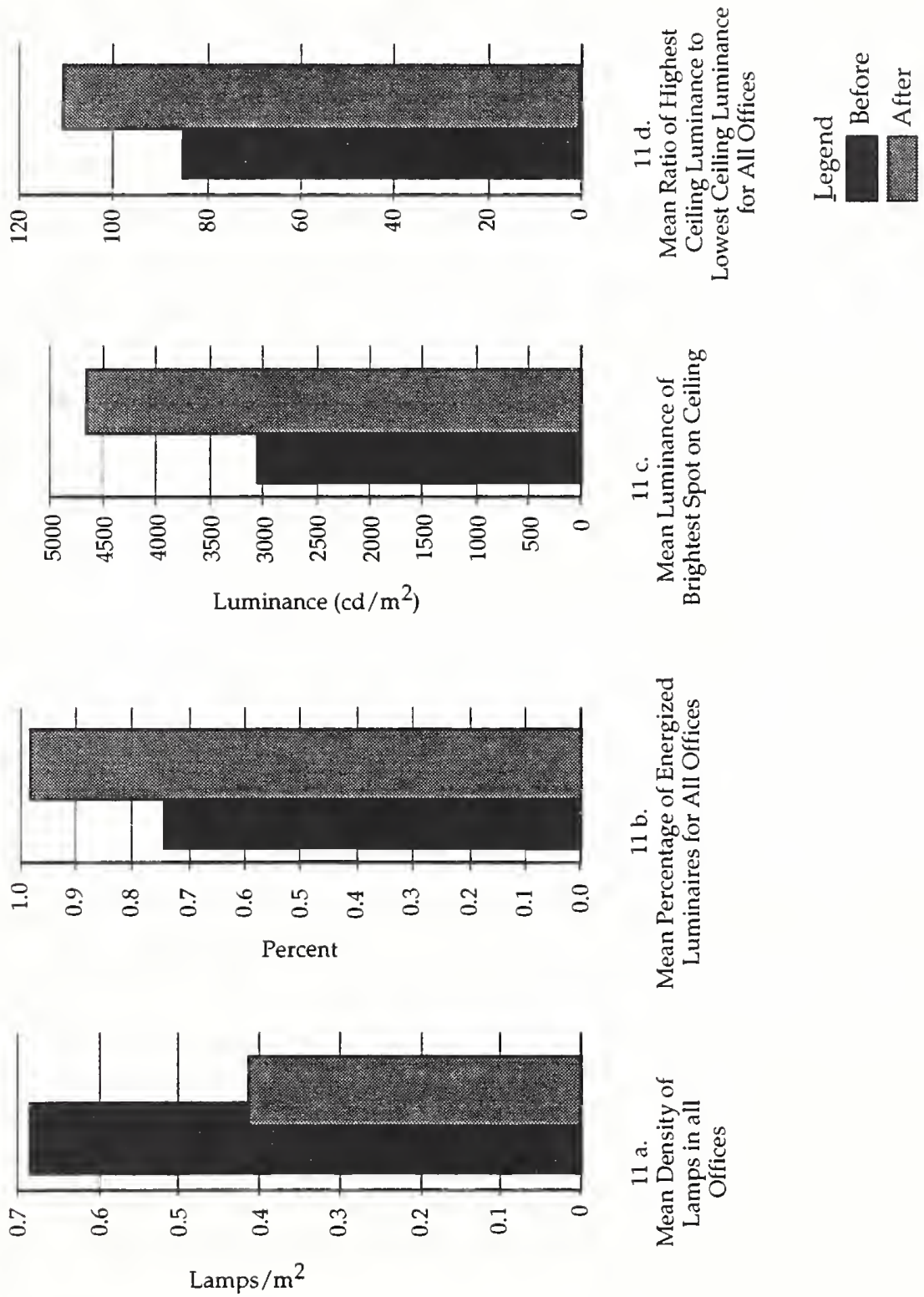
Figure 12. Shifts in CIE x,y Coordinates for Color Samples as a Function of Sequence.

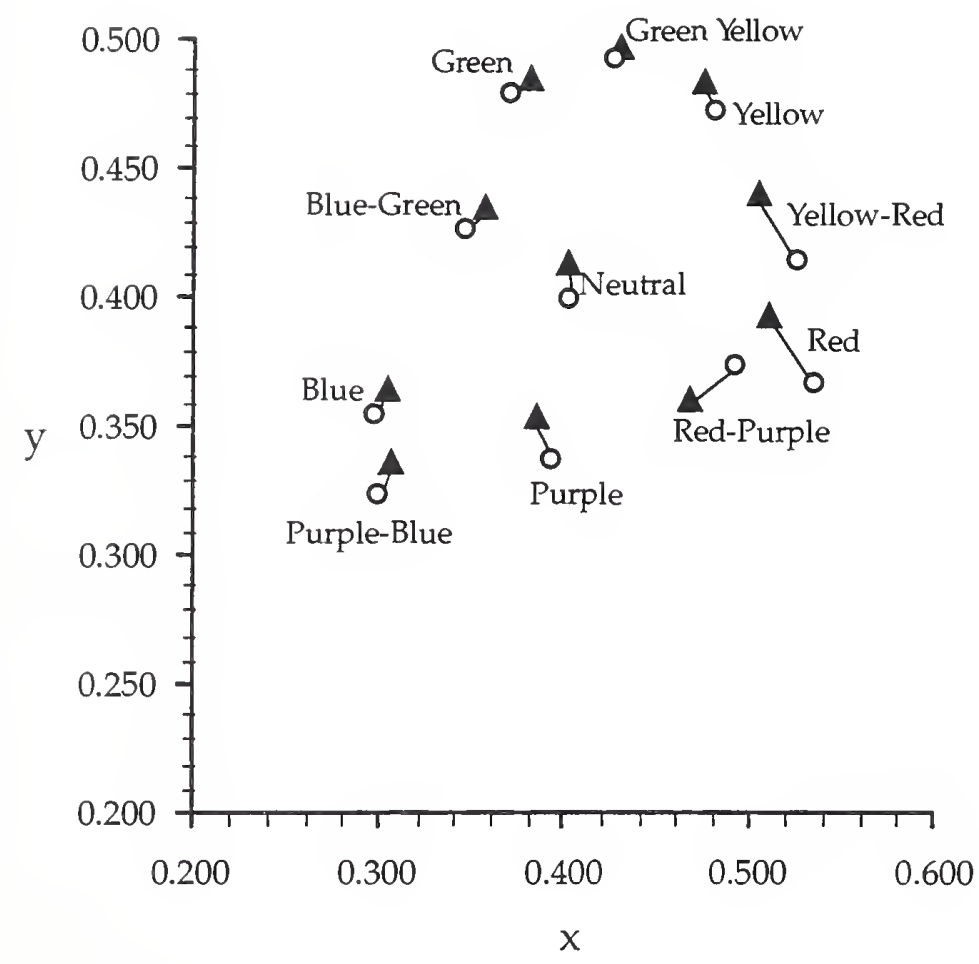

Color Name Munsell Value Yellow

Yellow Red

Red

5Y 8.5/10

Red Purple

Purple

5YR 7/10

$5 R$ R/10

Neutral

5RP $6 / 10$

Green Yellow

$5 \mathrm{P} 6 / 8$

N6

Green

Blue Green

$5 \mathrm{GY} 8 / 8$

Blue

$5 B G 7 / 6$

Purple Blue

$5 \mathrm{~PB} 6 / 10$

Legend

A Before

- After 
Figure 13 summarizes the temperature and humidity data. It is important to realize that the significant shifts observed here are most likely due to changes in the external weather: the data in December 1993/January 1994 (After) were collected during a severe cold snap on a series of overcast, snowy days. The data in March of 1993 (Before) were collected under sunny conditions when the sun angle was low en ough to allow considerable solar heat gain. Figure 13a reinforces this point with a significant decline in temperatures observed in all offices (regardless of window orientation) after the retrofit. The decline was greatest for south-facing offices, suggesting that solar heat gain was a key cause of the March 1993 temperatures. It should also be noted that the mean temperatures observed for the south-facing and windowless offices were slightly above the ASHRAE norm of $23.6^{\circ} \mathrm{C}$ for winter temperatures. (These data agree with the fact that occupants tended to rate their offices as warm rather than cold.) All mean temperatures were well above the ASHRAE recommended winter low of $20^{\circ} \mathrm{C}$. In addition, the offices tended to be rather dry, particularly in the winter. Thus, figure 13b demonstrates quite a drop in relative humidity between the two measurements, with winter levels near 14 percent and spring levels near 27 percent. Again, the winter humidity levels are below those recommended by ASHRAE for comfort. Finally, figure 13c plots the percentage of offices having fans as a function of window orientation. Two locations emerge as having a significantly greater percentage of fans (more than 40 percent) - south-facing and windowless offices. This finding reinforces the idea that these offices were hotter and less comfortable than offices in other locations. Since fans are not provided by building management so that employees must supply their own, these data further support the idea that these offices were warm enough to force employees into action. An additional contributing factor to the decrease in temperatures following the retrofit may well have been the change to more efficient (cooler) lamps and ballasts which would contribute less heat to the office.

As noted in the text, Figures 9-13 demonstrate significant changes in task illuminance, wall illuminance, lamp density ambient temperature and humidity following the retrofit. The changes in illuminance and luminance were positive, and in the direction desired by DOE management and the retrofit team. 
Figure 13. Measured Temperatures and Humidity.
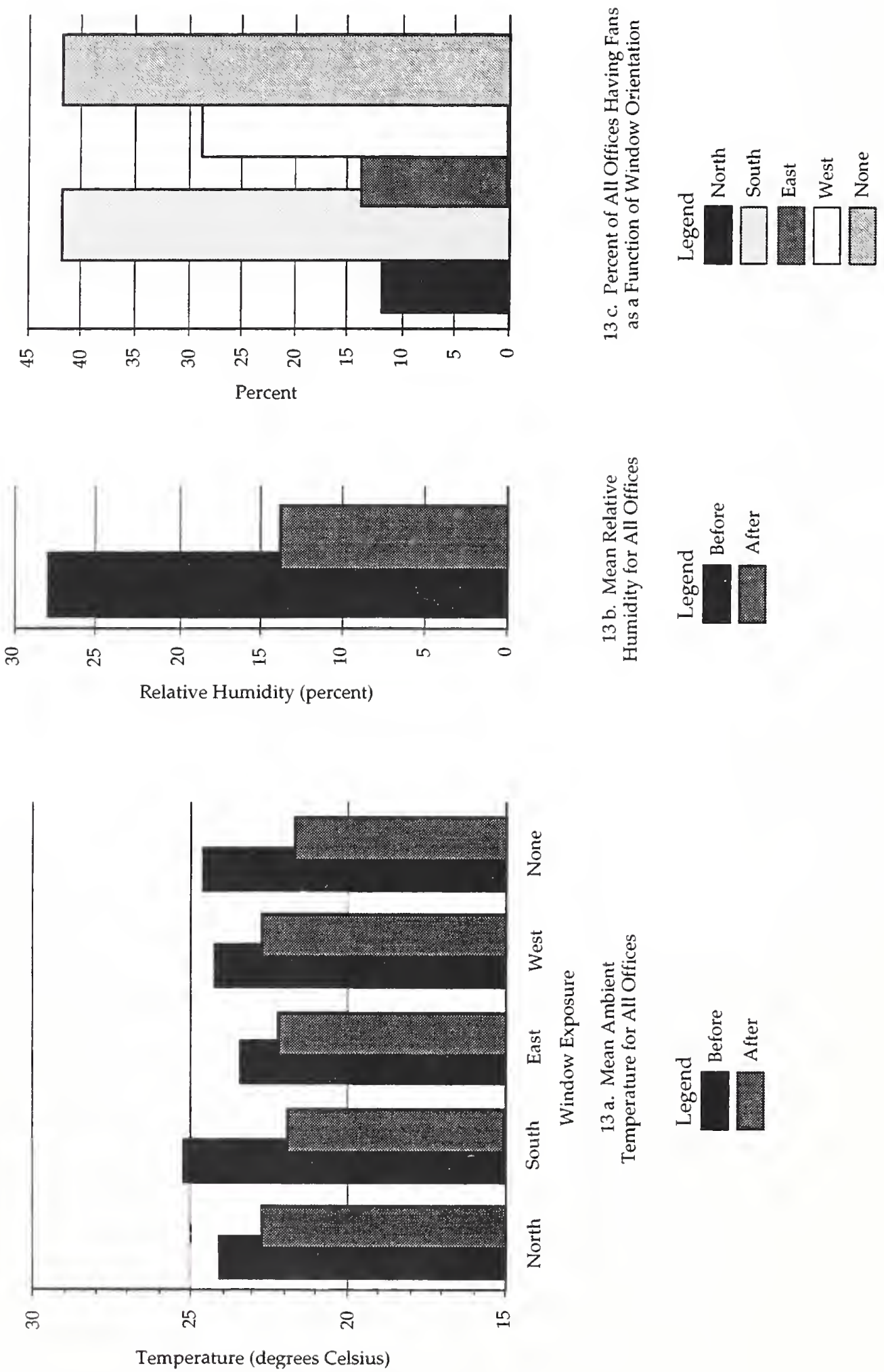
The data presented in the present report support the hypothesis that the relighting significantly improved the lighting conditions in the Forrestal Buildings. Consideration of the questionnaire data indicates that the items addressing lighting concerns were usually statistically significant - and more positive - when before and after retrofit conditions were compared. On the other hand, attitudes toward non-lighting components of the building environment (which were not actually changed as part of the retrofit) did not change significantly between the two surveys. At the same time, occupants continued to be somewhat negative about thermal and air quality conditions - thus reinforcing the hypothesis that lighting conditions had truly been improved. These data indicate clearly that occupants responded to changes in the lighting, rather than to other environmental variables.

The significant and positive response to the lighting questions is fundamentally important, indicating that occupants found the retrofit improved the general lighting conditions in their offices. After the retrofit, occupants found their spaces to be more pleasing, less poorly lit, and less glaring. They also rated the appearance of their lighting system and the quality of their lighting as better. Comparison with the earlier data reported by Collins, et al. (1989) suggests a more positive response to the lighting retrofit in the Forrestal Building. Mean ratings of lighting satisfaction were higher in the present study than in the previous study, reinforcing the idea that the lighting conditions had truly been improved. It is of course risky to compare mean ratings from two different studies, but the trend is toward more positive response for the Forrestal Building than for the small Army facilities.

Inspection of the physical data shows that the retrofit successfully improved the pattern of luminance in the offices, with fewer dark spots on the ceiling, and brighter surfaces on the upper portion of the walls. This is consistent with observations by Loe and his colleagues (1991) in England who determined that the central $40^{\circ}$ field is critical in determining satisfaction with lighting, and with Collins, et al. (1989) who found that occupants preferred more balanced luminance distributions in their offices. In addition, the measured task illuminance increased significantly, to levels above those specified by DOE. It should be noted that measured illuminance levels were significantly higher for those offices with windows, indicating that daylight made a significant contribution to the overall illuminance levels and luminance patterns in the offices. At the same time, occupants were quite negative about the absence of windows in windowless office areas, making many negative responses in the comment section of the questionnaire. Their comments reinforced the conclusions drawn by Collins (1974) and Ulrich (1984) about the importance of windows to people in offices and other relatively confined spaces.

In conclusion, the retrofit improved attitudes toward the lighting for a significant number of building occupants. It also improved the lighting for physical measures such as task illuminance and surface luminance. Thus the goals of the retrofit - to improve the existing lighting appearance and quality while providing more efficient lighting systems - were met. 
Post-occupancy evaluations (POEs) are very complex projects. They attempt to provide some understanding of how built environments influence the attitudes and beliefs that occupants hold about the environment in which they work and how that environment may affect their job performance. The evaluation could address any single facet of a built environment such as acoustics, thermal comfort, or lighting; or it could address all of them at the same time. The present POE has primarily addressed the lighted environment.

Since POEs are complex and address many interacting variables, their success relies overwhelmingly on the planning and execution of the project, which itself revolves around the sensitivity of the planned statistical analyses and the potential variability of the data.

The first goal of any project is to accumulate a set of data which will yield statistically significant results. This does not mean manipulating data to yield desired results, but rather exercising proper experimental design techniques to yield results that accurately represent reality. Designing an experiment to yield such a data set is not a trivial task and requires great skill. However, a few basic principles can serve as a solid foundation. The remainder of this section describes the fundamental requirements and approaches necessary for executing a POE. The descriptions are largely based on the experimental instruments used for this analysis because they have been developed over the course of many projects and have been found successfully to discriminate occupant responses to changes in lighting.

\subsection{Determining the Sample Size and Composition}

A successful POE is based on two data sets: one which is a compilation of the responses to a questionnaire administered to the building occupants, and a second one which contains an inventory of physical measures of the space. It is usually not cost effective to administer a questionnaire to all occupants because the building is too large. In this case, a sample must be selected which is large enough to accurately represent the population of the facility and permit statistical robustness. At the same time, the sample should be manageable in terms of minimizing disruptions to the building staff and the difficulty of data collection and subsequent transcription and analysis.

Sample size is dictated by the anticipated variability of the data to be collected and the number of factors of interest in the evaluation. But, since the data are yet to be collected and the variability is therefore unknown, the exact sample size remains elusive. There are, however, some rules of thumb. First, collect as much data as can be afforded. Excess data are never wasted but too little data are a complete waste. Generally, small samples provide data which are highly variable, irregular, and not representative of the population. As such, the statistical procedures and tests are unable to discriminate what could potentially be very small, but significant, differences. Larger samples provide more stable data because they include a much 
larger portion of the population. Therefore, the statistical analyses are less likely to provide false interpretations of the data.

Secondly, the questionnaire data should be provided by a sample of employees that represents the work force. This means that the sample should include proportionate numbers of employees from different administrative levels, such as managers, administrative staff, the main work force, secretarial staff, and perhaps maintenance staff. This is important because each job classification has different responsibilities which dictate the exact nature of the visual (or other) tasks that are completed within a space. The exclusion of a particular group may skew the data set and provide unwarranted importance to a particular measure which is ultimately unimportant. Other demographic factors that may be of interest are age distribution and visual capacities. It would be unwise to collect data about the quantity of light only from young employees if a large portion of the population is older, since older people may require more light to complete their tasks. The fundamental point is that the various factors that affect visual or task performance should be accurately represented in the sample. These factors include task type, which is determined by job description, the age of the workers, and the gender of the workers since gender may not be balanced within all job categories.

Just as a number of factors influence the subjective data set, an equally large number of factors affect the data set for the physical inventory. These include the presence and directional orientation of windows, the types of electric lighting systems, the geometrical configuration of the office (whether it is a private office, shared office, or an open office plan), and the location of the space within the facility. Also, in a multi-use facility where not all the spaces are conventional offices, the space usage may become a factor of interest. In short, the sample of rooms should proportionately reflect the nature of the building (or at least areas of interest) and should be selected from all areas of the facility.

Choosing the samples as representative of the building population or of the facility itself is a necessary, but not a sufficient, condition for a successful POE. The sufficient condition is interfacing the requirements for the subjective sample with the requirements based on the sample required for the physical spaces of interest. After accounting for all the factors of interest, the next critical requirement for selecting a sample is that it must be a random selection from the target population. Failure to select a random sample will impose unwanted constraints on the data and will prohibit a legitimate statistical analysis.

Since the sample size is dependent upon the different factors of interest, it is difficult to suggest an actual sample size. However, as the number of factors increases, so does the sample size. Ultimately, the sample size for each data set will likely be at least a hundred. We used 350 in the present study, for example, while Collins, et al. (1989) used about 700 for the questionnaire sample in their study. For questionnaire data, it is important to inflate the sample size by about fifty percent over the minimum number of data points needed for a proper analysis because only about one third of the distributed surveys can be expected to be returned. The final number of spaces targeted for the physical inventory may be much less 
than the questionnaire sample if, as in the present study, many of the physical spaces are virtually identical. We studied 100 spaces initially and 75 after the retrofit, and found this to be a reasonable number with relative low variability among spaces.

Two further goals in selecting samples which enhance the validity of a POE are to choose the same physical spaces occupied by survey respondents and to distribute the questionnaire to the same sample of respondents both before and after the modifications. By measuring the physical spaces actually occupied by survey respondents, the two data sets will more accurately reflect the relationship between the occupants and their work spaces. Distributing the questionnaire to the same sample both before and after the modifications will make it easier to establish a reliable trend in the data. If at all possible, it is extremely desirable to assign subjects identification codes which maintain their anonymity and yet permit the data they supply before and after environmental modifications to be paired. Paired data allows for a more reliable statistical analysis, especially if the sample size is small. The importance and significance of this suggestion cannot be overemphasized. It is often very difficult to implement in practice, however.

\subsection{Suggested Questionnaire Contents}

The design of a questionnaire is equally important as choosing a good sample. Questionnaires should not reflect any experimental bias and should contain self-validation structures. In other words, the questionnaire should address a given number of points. These points should be addressed by posing a few questions in very generic, non-leading terms. In addition, several points should be addressed several times in different terminology. In this way, if all the questions pertaining to a given point reflect similar responses, it can be concluded that the responses are valid and respond to the theme of the question, rather than being influenced by the wording of the question. Another important consideration in designing a questionnaire is that the questions should not "lead" the respondent. Rather, the items of interest should be disguised by adding a few items of related interest. This deters subjects from fully understanding the intent of the questionnaire so that they are less likely to provide the data they think the experimenter wants. This is a critical consideration because, although human nature is to want to perform well, questionnaires should not be performance measures. Along the same lines, the precise nature of the experiment should not be described to the subjects because, again, if they are aware of the goals, they will tend to provide, often unconsciously, skewed data which is not representative of the conditions. For this reason, physical measures should be made ideally after the questionnaires have been returned; and the questionnaires should not be administered immediately after any modifications to the facility.

The questionnaire used in the current POE is included in Appendix A and can be considered a good model of the types of questions that should be included in a evaluation of lighted environments. This questionnaire is based heavily on those used in previous post-occupancy evaluation research conducted by NIST and has been refined with each implementation. The 
current form is effective in eliciting responses to physical conditions in buildings and is recommended for subsequent evaluations.

\subsection{Suggested Physical Measurements}

The physical measurement form suggested for the model POE has been modified and shortened from that used in the Forrestal Building to reflect more useful measurements. The original form proved to be overly complex for the type of results we obtained. The revised form given in Appendix B concentrates on measures of lighting that can be easily taken, analyzed, and related back to the subjective data. It is similar to forms used in previous POE research at NIST.

The lighting measures of interest are task illuminance and luminance because these reflect the quantity of light falling on the task and the task contrast. Both quantities are critical to assessing task visibility. Wall illuminance and luminance are also important because they very simply describe the distribution of light within the space, which influences the perception of the space. The color measurements allow some quantification of how "normal" a space appears. Depending on the color rendering capability of the lamps chosen, colors may not appear normal and may, in fact, affect worker productivity if color discrimination is a part of the task requirements. In the current study, the color measurements quantified the increased capability of the new lamps to render colors more realistically and also validated occupant reports of a difference in the appearance of colors in their spaces. It is important to take physical measures using the same procedure and location in each office. Using standard tasks and calibrated equipment is essential to obtaining reliable, accurate data. Fundamentally, the physical measures should, in some way, reflect the items on the questionnaire so that they can be used to support or refute subjective responses. If they support the responses, it is likely that the subjective responses are real and are legitimate. If the physical measures do not corroborate the subjective reports, this is a clear sign that other underlying factors are influencing the data. In essence, both sets of data validate each other.

$$
\text { Collecting and Analyzing the Data }
$$

After the experimental approach has been developed, administering the questionnaire and collecting the physical inventory is relatively straightforward. As a basic precaution, any discussion with the subjects in the building should be kept vague until all of the data is collected. Any conversations or written material that contain too much information about the intent of the study and how the questionnaire and physical measures relate to each other could influence the subjective data. Participants should be debriefed at the conclusion of the study and given an opportunity to provide further comments, however.

Both sets of data should be collected before and after the modifications to the building are made. The preliminary, or baseline, data should be collected before the employees are too involved in the upcoming changes to the space because their knowledge about the proposed 
changes could influence their response. The post-modification data should be collected a few months after the modifications are completed. This allows the novelty of the new environment to wear off and will allow more representative data to be provided.

After the subjective data are collected, they should be analyzed for at least one dimension: namely, sequence (before and after modifications). In addition, it is helpful to analyze the data for other suspected significant factors, such as window orientation or office type if the offices are of mixed types. The statistical analysis should be an analysis of variance because it is a robust statistical procedure that reduces the possibility that non-significant data are mistaken for significant data. Finally, multiple comparisons of the significant results should be made to identify precisely which levels of a particular factor contribute to the significance. Standard statistical text books, such as Howell (1982), describe these methods. As with the questionnaire data, the physical measurements should be subjected to an analysis of variance. Follow-up statistical tests should be used to isolate which levels of a statistically significant factor are different from one another.

The statistical analyses should be performed using a computer, since hand calculations are extremely time-consuming. Since statistical analysis packages can be expensive to purchase and require some expertise to use successfully, it may be advantageous to consult a statistician to help design the experiment and analyze the data. Statisticians possess the tools and the necessary knowledge to complete such an analysis. Successful experimental design and data analysis critically depend on a complete understanding of the assumptions of the statistical tests to be performed and the proper collection of both physical and subjective data.

Ultimately, the data from both analyses should be compared to determine the overall impact of any relighting or environmental improvement. In addition, it is helpful to compare the current findings to the findings from other similar evaluations. This comparison offers the opportunity to validate the completed study and identify potential problems or areas of the questionnaire or physical measurement protocols that could benefit from revision.

As stated earlier, POEs are extremely complex studies. They attempt to corroborate changes in subjective evaluations of built environments before and after an environmental change with changes in physical measures of the same environment. Because of these complexities, section 6 of this document has attempted to provide some guidance for conducting a POE. While it does not attempt to outline all of the statistical assumptions and precautionary measures which are important for a successful POE, it does highlight the basic requirements and provides a good foundation for completing a POE of lighted environments. 
American Society for Heating, Refrigerating and Air-Conditioning Engineers (ASHRAE). Atlanta, GA. 55-1981.

Boyce, P.R. Investigations of the subjective balance between illuminance and lamp color properties. Lighting Research and Technology, 1977, 2, Pp. 11-24.

Collins, B.L. Windows and People. Washington, D.C. NBS BSS 70, June, 1975.

Collins, B.L. Evaluation of the Role of Luminance Distributions in Occupant Response to Lighting, Proceedings, National Lighting Conference, Cambridge, April 1990, Pp. 1-10.

Collins, B.L, Gillette, G.L., Dahir, M.S. , Goodin, P.J. Post-Occupancy Evaluation of Several U.S. Government Buildings. Gaithersburg, MD: NIST, NISTIR 89-4175, September 1989.

Collins, B.L., Fisher, W.S, Gillette, G.L., Marans, R.W. Evaluating Office Lighting Environments: Second Level Analysis. Gaithersburg, MD: NIST, NISTIR 89-4069, Apr. 1989.

Collins, B.L. and Rubin. A.I. Analysis of Work Environment Data from Three Army Field Stations. Gaithersburg, MD: NIST, NISTIR 88-3871, October 1988.

Dillon, R., and Vischer, J.C. Derivation of the Tenant Questionnaire Survey Assessment Method: Office Building Occupant Survey Data Analysis. Ottawa, Canada: Public Works Canada, AES/SAG 1-4:87-9, November 1987 (b).

Dillon, R., and Vischer, J.C. User Manual: Tenant Questionnaire Survey. Ottawa, Canada: Public Works Canada, AES/SAG 1-4:87-8, November 1987 (a).

Flynn, J.E., Spencer, T.J., Martyniuk, O., and Hendrick. C. Interim Study of Procedures for Investigating the Effect of Light on Impression and Behavior. Journal of the Illuminating Engineering Society, 1973, Pp. 87-94.

Gillette, G., and Brown, M. Occupant Evaluation of Commercial Office Lighting: Volume I., Methodology and Bibliography. ORNL/TM-10264/V1, Oak Ridge National Laboratory, November, 1986.

Gillette, G. Evaluating Office Lighting Environments: Reference Lighting Power Density Data. Gaithersburg, MD: NBS, NBSIR 88-3691, January, 1988.

Gillette, G., and Brown, M. Occupant Evaluation of Commercial Office Lighting: Volume III., Data Archive and Database Management System. ORNL/TM-10264/V2, Oak Ridge National Laboratory, August, 1987. 
Hawkes, R.J., Loe, D.L., and Rowlands, E. A note towards the understanding of lighting quality. Journal of the Illuminating Engineering Society, 1979, Jan, Pp. 111-120.

Howell, D.C. Statistical Methods for Psychology, 1982, Boston:PWS-Kent.

Kaufman, J. E. (Ed). IES Lighting Handbook, Fifth Ed. New York: Illuminating Engineering Society, 1972.

IES Lighting Handbook: 1987 Application Volume and IES Lighting Handbook: 1984 Reference Volume. Illuminating Engineering Society of North America, 345 East 47th Street, NY, NY 10017, 1987, 1984.

Loe, D.L., Mansfield, K.P., and Rowlands, E. Light patterns and their relevance to spatial appearance and the quality of the lit environment. CIE Proceedings - 22nd Session, Melbourne, Australia, 1991, Pp. 41-44.

Louis Harris Associates for Steelcase. The Office Environment Index: 1987 Full Report, and 1987 Summary Report. Steelcase, 1987.

Marans, R. W. Evaluating office lighting environments: A further report. Lighting Design and Application, 1987, 17, p. 32-36, 51.

Marans, R. W., and Brown, M. Occupant Evaluation of Commercial Office Lighting: Volume II. Preliminary Data Analysis. ORNL/TM-10264/V2, Oak Ridge National Laboratory, November, 1987.

Meyer, B. Indoor Air Quality. Reading, MA: Addison-Wesley Pub. Co., 1983.

Rea, M. Towards a model of visual performance: Foundations and data. Journal of the Illuminating Engineering Society, 1986, 15, pp. 41-57.

Rubin, A.I. and Collins, B.L. Interim Survey of Selected Military Building Environments: A Research Approach. Gaithersburg, MD: NBS, NBSIR 87-3606, August 1987.

Rubin, A.I. and Collins, B.L. Evaluation of the working environment at selected U.S. Army field stations: Suggestions for Improvement. Gaithersburg, MD: NBS, NBSIR 88-3827, August 1988.

Ulrich, R.S. View through a window may influence recovery from surgery. Science. 1984, 224 , pp. $420-421$. 
Appendix A. Suggested Questionnaire Items

Today's Date:

Office Suite:

South West

Building:North

Corridor:

Room No.:

Part A. Instructions: Please indicate the extent to which you agree with each of the following statements by circling the appropriate number. If a statement does not apply to you, do not circle any of the numbers.

\section{Coding Scheme: \\ 1 \\ 2 \\ 3 \\ 4 \\ 5}

1. I have enough work space to perform my job.

2. The amount of light on my work allows me to see it clearly.

3. I create shadows on my work because my body blocks the light.

4. The ceiling lights in my work area are glaring.

5. The lighting in my office is pleasing.

6. The colors in my office appear natural.

7. My work is important to the every day functioning of this office.
Strongly Agree

Somewhat Agree

Neutral

Somewhat Disagree Strongly Disagree

$\begin{array}{lllll}1 & 2 & 3 & 4 & 5\end{array}$

$\begin{array}{lllll}1 & 2 & 3 & 4 & 5\end{array}$

$\begin{array}{lllll}1 & 2 & 3 & 4 & 5\end{array}$

$\begin{array}{lllll}1 & 2 & 3 & 4 & 5\end{array}$

$\begin{array}{lllll}1 & 2 & 3 & 4 & 5\end{array}$

$\begin{array}{lllll}1 & 2 & 3 & 4 & 5\end{array}$

$\begin{array}{lllll}1 & 2 & 3 & 4 & 5\end{array}$ 
8. If I could, I would turn some lights in my office off because they are too bright.

9. My space is confining.

10. Noise keeps me from doing my job well.

11. The air circulation in my office is adequate.

12. The overall appearance of offices and workspaces is pleasing.

13. My office is colorful.

14. The irregular pattern of lighted ceiling lights in my work area bothers me.

15. I would like to have an adjustable light on my desk.

$\begin{array}{lllll}1 & 2 & 3 & 4 & 5\end{array}$

16. Overall, I am satisfied with my workspace and furniture.

17. My space is poorly lighted.

18. I am satisfied with the quality of my work.

$\begin{array}{lllll}1 & 2 & 3 & 4 & 5\end{array}$

19. The lighting in my office is too dim.

20. The amount of light in my office washes out the computer display.

21. My office is humid.

22. I am able to easily adjust my viewing distance to the computer screen.

23. The overhead lights create distracting reflections in my computer screen.

24. My computer screen has an anti-glare device.

25. I can easily adjust the brightness of my computer display.

26. My office is cold. 
27. The lighting in my office is too bright.

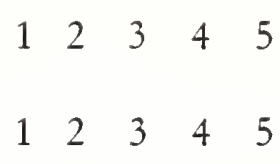

28. The lights in my work area make a loud humming/buzzing sound.

29. My space is stimulating.

$\begin{array}{lllll}1 & 2 & 3 & 4 & 5\end{array}$

30. I am satisfied with the lighting in my work space $\begin{array}{lllll}1 & 2 & 3 & 4 & 5\end{array}$

31. My office is hot. $\begin{array}{lllll}1 & 2 & 3 & 4 & 5\end{array}$

32. The work atmosphere in my office is tense. $\begin{array}{lllll}1 & 2 & 3 & 4 & 5\end{array}$

33. The space is adequate for my job. $\begin{array}{lllll}1 & 2 & 3 & 4 & 5\end{array}$

34. My space appears spacious.

Part B. Instructions: Please evaluate the following items by circling the appropriate number.

Coding Scheme:

$\begin{array}{ll}1 & \text { Excellent } \\ 2 & \text { Good } \\ 3 & \text { Adequate } \\ 4 & \text { Fair } \\ 5 & \text { Poor }\end{array}$

1. Amount of space for your work.

$\begin{array}{lllll}1 & 2 & 3 & 4 & 5\end{array}$

2. The quality of the lighting in the corridors and hallways.

$\begin{array}{lllll}1 & 2 & 3 & 4 & 5\end{array}$

3. Condition of desks and chairs.

$\begin{array}{lllll}1 & 2 & 3 & 4 & 5\end{array}$

4. Noisiness of the space.

$\begin{array}{lllll}1 & 2 & 3 & 4 & 5\end{array}$

5. Amount of lighting.

$\begin{array}{lllll}1 & 2 & 3 & 4 & 5\end{array}$

6. Color of furniture and objects.

$\begin{array}{lllll}1 & 2 & 3 & 4 & 5\end{array}$ 
7. The quality of the lighting in the conference rooms.

$\begin{array}{lllll}1 & 2 & 3 & 4 & 5\end{array}$

8. Conversational privacy.

$\begin{array}{lllll}1 & 2 & 3 & 4 & 5\end{array}$

9. Maintenance of the space.

$\begin{array}{lllll}1 & 2 & 3 & 4 & 5\end{array}$

10. Appearance of the lighting system.

$\begin{array}{lllll}1 & 2 & 3 & 4 & 5\end{array}$

11. Ability to adjust light for work.

$\begin{array}{lllll}1 & 2 & 3 & 4 & 5\end{array}$

12. The quality of the lighting in my work space.

$\begin{array}{lllll}1 & 2 & 3 & 4 & 5\end{array}$

13. Ventilation and air circulation.

$\begin{array}{lllll}1 & 2 & 3 & 4 & 5\end{array}$

14. Pleasantness of the space.

$\begin{array}{lllll}1 & 2 & 3 & 4 & 5\end{array}$

15. Room temperature.

$\begin{array}{lllll}1 & 2 & 3 & 4 & 5\end{array}$

16. Cleanliness of the space.

$\begin{array}{lllll}1 & 2 & 3 & 4 & 5\end{array}$

17. The quality of the lighting in the restrooms.

$\begin{array}{lllll}1 & 2 & 3 & 4 & 5\end{array}$

18. The appearance of the work spaces and offices.

$\begin{array}{lllll}1 & 2 & 3 & 4 & 5\end{array}$

Follow-up:

Did you complete this same survey in [Insert date of

Yes No questionnaire distribution prior to modifications.

This question should only be included on the post-modification survey?

On the average, how many hours during the day are the lights in your office turned on?

$$
\begin{array}{lllll}
0-2 & 2-4 & 4-6 & 6-8 & 8+
\end{array}
$$

On the average, how many hours per day do you work at a personal computer?

$$
\begin{array}{lllll}
0-2 & 2-4 & 4-6 & 6-8 & 8+
\end{array}
$$

On the average, how many hours per day do you spend reading and writing paper tasks?
$0-2$
$2-4$
4-6
6-8
$8+$ 
Part C. For this portion of the survey, please record your response directly on these sheets by placing an $\mathrm{X}$ on the line preceding your choice Unless indicated otherwise, mark only one choice.

C1. How long have you worked in your current work space?
A. Less than 1 year
B. 1-2 years
C. 2-5 years
D. More than 5 years

C2. The window in my office faces
A. North
B. South
C. East
D. West
E. I don't have a window.

C3. Which of the following best describes your job?
A. Administrative
B. Clerical
C. Technical
D. Other. Please specify:

C4. Do you
A. Wear single vision glasses?
B. Wear Bifocals or Trifocals?
C. Wear Contact Lenses?
D. None of the Above.

C5. How old are you?
A. less than 20
B. $20-29$
C. $30-39$
D. $40-49$
E. 50-59
F. 60 or over 
C6. Suppose you could make 4 changes to your overall work environment. Using the list below, indicate the 4 changes you would make in order of preference (where $1=$ most preferred.

A. More comfortable day-to-day temperatures

B. More privacy

C. Change in color of furnishings or carpet

D. Improved lighting

E. Less noise

F. Improved air circulation

G. More surface area for work

H. More comfortable furnishings

I. More frequent cleaning

J. Adjustable task lighting

K. More adjustable chair

L. View out/daylight

M. Other

C7. Please explain the reasons for the four choices you made in question C6.

Choice 1:

Choice 2:

Choice 3:

Choice 4:

This question was added for the second questionnaire

C8. How does the newly installed lighting in your office compare to the old lighting?

Thank you very much for your participation! 
Appendix B. Suggested Physical Measurement Form

Location Number:

Today's Date:

Current Time:

DOE/POE

Environmental Measures

Room Inventory

A. Workstation Dimensions Length Width Height

1. Office Area

2. Desk

3. File Length

B. Luminaires

Active Inactive Total

1. Number of Luminaires/Work Space

2. Number of Lamps/Luminaire

3. Number of Lamps/Work Space

4. Control/Switching

None

On/Off

C. Photometric Measurements

WITH TASK LIGHT ON

1. Worksurface Illuminance (lx):

Mean Illuminance

\begin{tabular}{|l|l|}
\hline Far Left & Far Right \\
\hline Near Left & Near Right \\
\hline
\end{tabular}


Location Number:

2. Task Luminance $\left(\mathrm{cd} / \mathrm{m}^{2}\right)$

Gloss Black

Matte Black

Gloss White

Matte White

3. Room Surface Illuminances (lux):

\begin{tabular}{|l|l|l|l|l|l|}
\hline & $\begin{array}{l}90 \text { degrees } \\
\text { to the Left }\end{array}$ & $\begin{array}{l}45 \text { degrees } \\
\text { to the Left }\end{array}$ & $\begin{array}{l}\text { Straight } \\
\text { Ahead }\end{array}$ & $\begin{array}{l}45 \text { degrees } \\
\text { to the Right }\end{array}$ & $\begin{array}{l}90 \text { degrees } \\
\text { to the } \\
\text { Right }\end{array}$ \\
\hline $2 \mathrm{~m} \mathrm{AFF} *$ & & & & & \\
\hline $1 \mathrm{~m} \mathrm{AFF}$ & & & & & \\
\hline
\end{tabular}

"Above Finished Floor

4. Room Surface Luminances $\left(\mathrm{cd} / \mathrm{m}^{2}\right)$ :

\begin{tabular}{|l|l|l|l|l|l|}
\hline & $\begin{array}{l}90 \text { degrees } \\
\text { to the Left }\end{array}$ & $\begin{array}{l}45 \text { degrees } \\
\text { to the Left }\end{array}$ & $\begin{array}{l}\text { Straight } \\
\text { Ahead }\end{array}$ & $\begin{array}{l}45 \text { degrees } \\
\text { to the Right }\end{array}$ & $\begin{array}{l}90 \text { degrees } \\
\text { to the } \\
\text { Right }\end{array}$ \\
\hline $2 \mathrm{~m} \mathrm{AFF}^{*}$ & & & & & \\
\hline $1 \mathrm{~m} \mathrm{AFF}$ & & & & & \\
\hline
\end{tabular}

"Above Finished Floor

5. Ceiling: Brightest (Furthest Luminaire):

Darkest: $\mathrm{cd} / \mathrm{m}^{2}$ $\mathrm{cd} / \mathrm{m}^{2}$ 
Location Number:

D. Supplemental Task Lighting

1. Which task location? Primary Secondary None

2. Lamp Type

3. Mounting:

Free Standing/Movable Under Cabinet

Desk Mounted/Movable

$\begin{array}{ll}\mathrm{Y} & \mathrm{N} \\ \mathrm{Y} & \mathrm{N} \\ & \mathrm{Y}\end{array}$

Other

4. Height Above Task Surface $\mathrm{cm}$

E. Photometric Measurements

WITH TASK LIGHT OFF

1. Worksurface Illuminance $(\mathrm{lx})$ :

Mean Illuminance

\begin{tabular}{|l|c|}
\hline Far Left & Far Right \\
\hline Near Left & Near Right \\
\hline
\end{tabular}

2. Task Luminance $\left(\mathrm{cd} / \mathrm{m}^{2}\right)$

Gloss Black

Matte Black

Gloss White

Matte White 
3. Room Surface Illuminances (lux):

\begin{tabular}{|l|l|l|l|l|l||}
\hline & $\begin{array}{l}90 \text { degrees } \\
\text { to the Left }\end{array}$ & $\begin{array}{l}45 \text { degrees } \\
\text { to the Left }\end{array}$ & $\begin{array}{l}\text { Straight } \\
\text { Ahead }\end{array}$ & $\begin{array}{l}45 \text { degrees } \\
\text { to the Right }\end{array}$ & $\begin{array}{l}90 \text { degrees } \\
\text { to the } \\
\text { Right }\end{array}$ \\
\hline $2 \mathrm{~m} \mathrm{AFF*}$ & & & & & \\
\hline $1 \mathrm{~m} \mathrm{AFF}$ & & & & & \\
\hline
\end{tabular}

4. Room Surface Luminances $\left(\mathrm{cd} / \mathrm{m}^{2}\right)$ :

\begin{tabular}{|l|l|l|l|l|l||}
\hline & $\begin{array}{l}90 \text { degrees } \\
\text { to the Left }\end{array}$ & $\begin{array}{l}45 \text { degrees } \\
\text { to the Left }\end{array}$ & $\begin{array}{l}\text { Straight } \\
\text { Ahead }\end{array}$ & $\begin{array}{l}45 \text { degrees } \\
\text { to the Right }\end{array}$ & $\begin{array}{l}90 \text { degrees } \\
\text { to the } \\
\text { Right }\end{array}$ \\
\hline $2 \mathrm{~m} \mathrm{AFF} *$ & & & & & \\
\hline $1 \mathrm{~m} \mathrm{AFF}$ & & & & & \\
\hline
\end{tabular}

"Above Finished Floor

5. Ceiling: Brightest (Furthest Luminaire): $\mathrm{cd} / \mathrm{m}^{2}$ Darkest: $\mathrm{cd} / \mathrm{m}^{2}$

F. Windows

1. Is there a window?

Y N

2. Orientation of the window:

$\begin{array}{llll}N & E & S & W\end{array}$

3. Does the task "see" the window? $\mathrm{Y} \quad \mathrm{N}$

4. Ratio of Window Area/Wall Area $\%$

5. Exposure ratios and Luminances

Sky Buildings $\mathrm{cd} / \mathrm{m}^{2}$

6. Shading Devices Used? Shades Curtains Venetian Portion of window occluded Blinds 
Location Number:

G. VDTs

1. Does the workstation have a VDT? $\mathrm{Y} \quad \mathrm{N}$

2. Can reflections of electric light sources be seen on the screen?

3. Is screen position adjustable?

Y N

Y N

4. Proximity of Window to SCREEN Behind Right Front Left

5. Check source document location

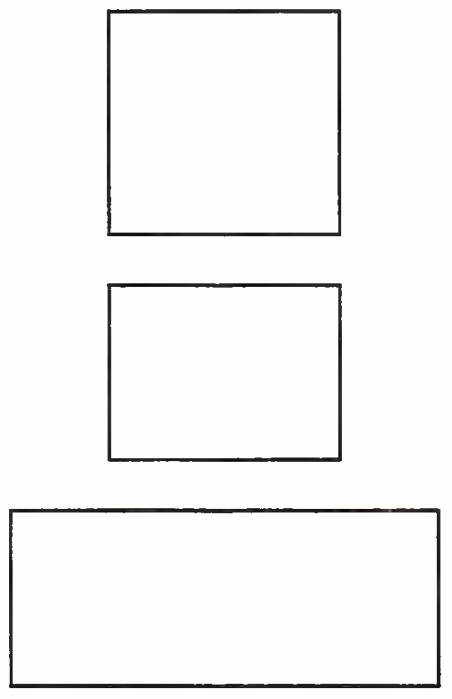

6. Source Document Photometry

a. Task Illuminance $(\mathrm{lx})$

b. Luminance $\left(\mathrm{cd} / \mathrm{m}^{2}\right)$ Task Light On

Gloss Black

Matte Black

Gloss White

Matte White 
Location Number:

H. Workstation Materials Wh

1. Dominant workstation color

$\begin{array}{lllllllll}R & O & Y & G & B u & P & B k & B r\end{array}$

Chromaticity coordinates

$\mathrm{x}$ y $\mathrm{Y}$

$\div \mathrm{E}$ $=\mathrm{P}$

2. Walls are predominantly

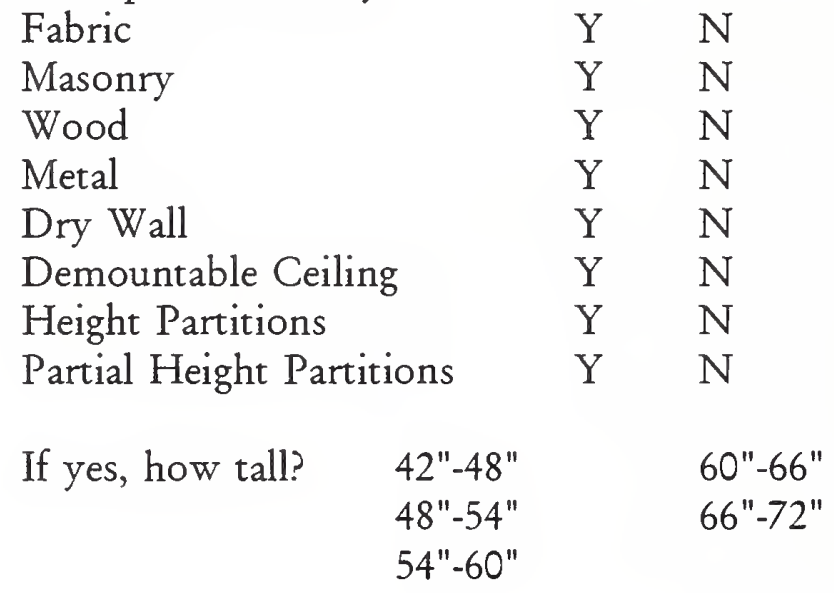

3. Workstation is an open area? $\mathrm{Y} \quad \mathrm{N}$

4. The space containing the workstation is

Private Shared (How many?

5. Furnishings:

Pictures or Posters on Wall

Pictures/mementos on desk,

Credenza, tack surface

Fan

Space Heater

$\begin{array}{cc}\mathrm{Y} & \mathrm{N} \\ \mathrm{Y} & \mathrm{N} \\ \mathrm{Y} & \mathrm{N} \\ \mathrm{Y} & \mathrm{N} \\ \mathrm{Y} & \mathrm{N}\end{array}$


Location Number:

G. VDTs

1. Does the workstation have a VDT? $\mathrm{Y} \quad \mathrm{N}$

2. Can reflections of electric light sources be seen on the screen?

3. Is screen position adjustable?

Y N

$\mathrm{Y} \quad \mathrm{N}$

4. Proximity of Window to SCREEN Behind Right Front Left

5. Check source document location

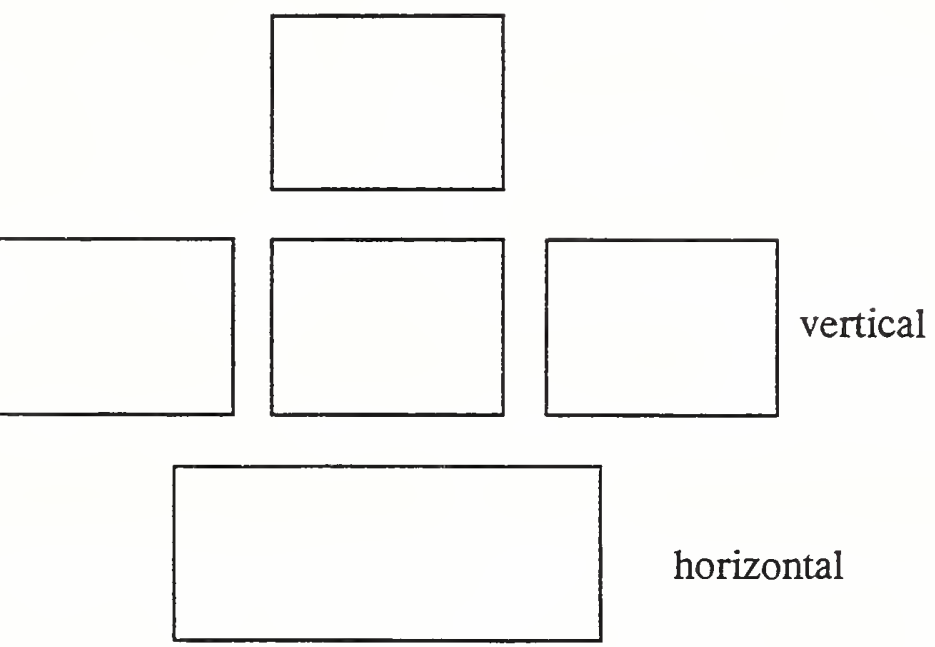

6. Source Document Photometry

a. Task Illuminance (lx)

b. Luminance $\left(\mathrm{cd} / \mathrm{m}^{2}\right)$ Task Light On

Gloss Black

Matte Black

Gloss White

Matte White 


